Article

\title{
Crime Risk Stations: Examining Spatiotemporal Influence of Urban Features through Distance-Aware Risk Signal Functions
}

\author{
Tugrul Cabir Hakyemez * and Bertan Badur
}

check for updates

Citation: Hakyemez, T.C.; Badur, B. Crime Risk Stations: Examining Spatiotemporal Influence of Urban Features through Distance-Aware Risk Signal Functions. ISPRS Int. J. Geo-Inf. 2021, 10, 472. https:// doi.org/10.3390/ijgi10070472

Academic Editor: Wolfgang Kainz

Received: 14 May 2021

Accepted: 8 July 2021

Published: 10 July 2021

Publisher's Note: MDPI stays neutral with regard to jurisdictional claims in published maps and institutional affiliations.

Copyright: (c) 2021 by the authors. Licensee MDPI, Basel, Switzerland. This article is an open access article distributed under the terms and conditions of the Creative Commons Attribution (CC BY) license (https:/ / creativecommons.org/licenses/by/ $4.0 /)$.
Department of Management Information Systems, Boğaziçi University, Sarıyer, 34342 Istanbul, Turkey; badur@boun.edu.tr

* Correspondence: tugrul.hakyemez@boun.edu.tr

\begin{abstract}
Static indicators may fail to capture spatiotemporal differences in the spatial influence of urban features on different crime types. In this study, with a base station analogy, we introduced crime risk stations that conceptualize the spatial influence of urban features as crime risk signals broadcasted throughout a coverage area. We operationalized these risk signals with two novel risk scores, risk strength and risk intensity, obtained from novel distance-aware risk signal functions. With a crime-specific spatiotemporal approach, through a spatiotemporal influence analysis we examined and compared these risk scores for different crime types across various spatiotemporal models. Using a correlation analysis, we examined their relationships with concentrated disadvantage. The results showed that bus stops had relatively lower risk intensity, but higher risk strength, while fast-food restaurants had a higher risk intensity, but a lower risk strength. The correlation analysis identified elevated risk intensity and strength around gas stations in disadvantaged areas during late-night hours and weekends. The results provided empirical evidence for a dynamic spatial influence that changes across space, time, and crime type. The proposed risk functions and risk scores could help in the creation of spatiotemporal crime hotspot maps across cities by accurately quantifying crime risk around urban features.
\end{abstract}

Keywords: spatiotemporal influence; spatial extent; crime risk function; crime risk strength; crime risk intensity

\section{Introduction}

Urban features correlate with crime patterns in their vicinity to varying degrees. By examining what differentiates this degree, researchers have primarily addressed the spatial influence that urban features have on spatial crime distribution in nearby areas [1]. This crime distribution represents the cumulative crime density at any point within the vicinity of an urban feature. Previous research showed that these density values change based on the distance from the exact location of an urban feature [2,3]. The distance decay effect, a well-established phenomenon in spatial crime research, characterized the spatial influence with a crime density inversely related to the distance from the origin point [1], due to the declining spatial interaction with urban features [4]. The spatial influence is at a maximum at the exact location and nearby areas (i.e., local effect) and decays throughout neighboring areas until it entirely dissipates at some distance (i.e., spatial diffusion effect) [5]. This dynamic crime density pattern, as a function of distance from the location, defines the spatial influence of an urban feature, and the distance stretching to the suggested dissipation point demarcates the spatial extent to which the spatial influence operates. Therefore, rather than a static indicator, a spatial influence should be measured by a distance-aware function that can estimate the crime density at any given point within a spatial extent. These functions allow for the development of multiple risk indicators that can help quantify the local and spatial diffusion effects within a given area.

Spatial influence does not exist in a vacuum. Rather, it is determined by the degree to which an urban feature interacts with environmental factors in creating a crime opportunity. 
From a routine activity perspective, this opportunity is characterized by a situation where a suitable target encounters a motivated offender under the absence of a capable guardian [6]. Crime pattern theory [7-9] spatializes these situations near urban features described as crime generators and crime attractors. While the former group caters to offenders by drawing large crowds, possibly containing a larger number of suitable targets, the latter has salient characteristics promoting criminal behaviors. In another attempt to explain the linkage between the spatial influence and crime opportunity, Groff [4] cited the level of human activity as a key factor. She argued that being exposed to larger volume of human activity for extended periods not only increases the spatial influence of an urban feature, but also stretches its spatial extent to further points. Based on this argument, we can maintain that it is the nearby human activity, rather than type of the urban feature, that drives the spatial influence. Supporting evidence is provided by Eck et al. [10] who found a highly asymmetric exposure to crime amongst urban features spread across a city, even in the same feature class. This asymmetric exposure can be jointly explained by urban mosaics [11] and a time geography perspective $[12,13]$. During a day, or a week, human activity traverses between urban mosaics that refer to the sub-regions of a city, each having unique urban layouts, activity patterns, and sociodemographic characteristics. This continuous shift in human activity between these mosaics' shapes the opportunity landscape across a city. Time geography, which articulates the limitations on human movement in space and time, provides further explanation for the direction of the indicated movement patterns. A typical example here would be the daily routine of an office employee. On a regular weekday, this employee follows a generic route: home, commute to work, workplace, and then back home. Similarly, the routes followed by people in large groups in entertainment areas during weekends is another example. These generic pathways move human activity back and forth between residential, business, and entertainment areas within a city. As a result, crime opportunity, hence the spatial influence of urban features in these areas, dramatically change over the course of a day and a week. In addition to human activity, sociodemographic characteristics also play an important role in shaping the crime opportunity around urban features. This relationship predicates upon an ecological perspective that views crime as a consequence of the social disorganization of an area. Accordingly, the lack of trust and solidarity amongst residents cripples the informal social control on crime [14], elevating the overall opportunity level in an area. This increased opportunity surrounds all the urban features and thus increases their spatial influence. Previous research provided sufficient empirical evidence on this linkage between sociodemographic characteristics and spatial influence $[15,16]$. Therefore, examining this linkage helps to further understand the interaction between spatial influence and social environment.

Lastly, the crime opportunity heavily relies on the crime type. Depending on the situational factors that define a crime setting, urban features have differential spatial influences on different types of crime [17]. This argument can be illustrated by a typical example. While a large crowd gathered around a fast-food restaurant may pose a great opportunity for the thieves dependent upon people's inattentiveness with regard to their personal belongings, the same crowd may act as a natural shield against a robbery that often involves a physical struggle between parties. As such, noticeable friction invites external intervention from capable guardians in the form of security forces and fellow citizens. These sharp differences in opportunity thus produce differential crime patterns around urban features. In sum, the operationalization of a spatial influence requires a crime-specific spatiotemporal approach. Accordingly, this approach should identify spatiotemporal influence, which is a term used herein to describe a spatial influence changing across space and time. Moreover, this influence should be crime-specific due to the significant variations in levels of associated crime opportunity for each crime type.

In this study, we introduced the concept of crime risk stations. This concept illustrates our crime-specific spatiotemporal approach to operationalizing the spatial influence of an urban feature within a spatial extent. Much like a base station broadcasts signals at varying strength levels throughout a coverage area, an urban feature operates like a 
crime risk station, broadcasting a signal-like spatial influence that changes over a spatial extent. The signal strength is maximum at the origin (i.e., local effect) and wanes while diffusing across nearby areas. Here, the broadcasting performance of a crime risk station can not only be evaluated by the strength of its spatial influence over a spatial extent, but also how much of the spatial influence it transmits from to the same extent (i.e., spatial diffusion effect). While higher transmission rates indicate higher spatial influence strength, lower rates demonstrate weaker ones. We hypothesized that the strength of the signal-like spatial influence dynamically changes based on space, time, and crime type. To test this hypothesis, we first developed distance-aware crime risk functions to capture the dynamic spatial influence of urban features on crime in nearby areas. Next, we operationalized the spatial influence with two novel risk scores, namely risk signal intensity score (RSIS) and risk signal strength score (RSSS). The first score indicates the cumulative crime density at a given spatial extent, while the second measures how much of the local effect is transmitted throughout the same spatial extent. Then, a spatiotemporal influence analysis statistically tested the differences in these scores across various models with different spatiotemporal configurations and crime types. Lastly, we examined the relationship between these scores and the social environment through a correlation analysis.

This study aimed to provide reasonable answers to the following questions:

1. How do the spatial influences of urban features change within a spatial extent?

2. How does a spatial influence operate within a spatial extent?

3. Based on a crime-specific spatiotemporal approach:

a. How does the spatial influence of an urban feature vary across the sub-regions of a city based on the time of day and the day of the week?

b. How does the spatial influence of an urban feature vary across crime types?

4. How does a crime-specific spatiotemporal influence interact with the characteristics of the social environment?

\subsection{Spatial Influence}

The spatial influence of an urban feature can be parameterized by the size of the surrounding crime opportunity field: a larger size indicates a larger spatial influence. The routine activities theory [2] formulated the idea that this opportunity is the result of a spatiotemporal convergence between a suitable target and motivated offender without any capable guardian present. Although it shed light on the how and why aspects of the crime opportunity, the theory does not elaborate where and when the crime opportunity emerges. A reasonable explanation came from Brantingham and Brantingham's [7] crime pattern theory, which put the opportunity into an urban context. Focusing on the opportunity fields around places, this theory [8,9] viewed urban features as activity nodes (i.e., the regularly visited places) and addressed two criminogenic node types: crime generators and crime attractors. The former type attracts a large volume of people with no crime-related motivations. The large crowds create situations that may tempt the occasional offenders who do not actively seek favorable offending situations, but have an intuitive vigilance to crime opportunities [18]. For instance, an opportunity would ensue for these offenders when a person waiting at a crowded bus stop left his/her bag unattended near his/her feet while reading something in a newspaper [19]. The latter type, crime attractors, is known to bear unique characteristics promoting criminal behavior. These nodes are frequented by offenders actively seeking crime opportunities as a part of their routine illegal activities. For instance, offenders are attracted to pubs near their closing hours in the hopes of finding suitable targets, often in the form of an intoxicated person unable to defend themselves properly $[20,21]$. In either type, the intensity of these opportunity fields indicates the spatial influence of an urban feature in nearby areas. Here, the answer to the question of "how near is near?" [1] is articulated by the spatial extent and brings up another line of research that will be discussed in the following section. 


\subsection{Characteristics of Spatial Extent}

Spatial extent demarcates the field of spatial influence where crime opportunity can be described as a function of the distance from an urban feature. Its magnitude is mainly parameterized by the volume of human activity: the exposure of an urban feature to larger crowds for extended periods indicates higher exposure to potential offenders, which not only stretches its spatial extent to further areas, but also elevates its spatial influence [4]. It has been repeatedly shown that spatial influence decays with distance and entirely dissipates at some point $[1,3]$ in parallel with the decreasing spatial interactions between urban features and crime [22].

Past researchers have proposed various distance thresholds for spatial extent, such as census blocks [21], face blocks [23], a quarter mile [24], one mile [25], or an arbitrary distance [26]. Noting that such a disk-like bandwidth may not properly capture fluctuations in spatial influence throughout a spatial extent in different physical layouts, researchers proposed multiple bandwidths at finer resolution levels to improve the precision of the analysis. This procedure starts with the placement of ring-like spatial buffers of various sizes from $1.7 \mathrm{~m}$ to $457.2 \mathrm{~m}[1,4,27,28]$ around urban features. Next, they calculated cumulative crime exposure at each buffer. In the last step, the buffer that demarcates the elevated crime exposure was selected as the spatial extent of the urban feature. As a remarkable example, using an average street block length (i.e., $122 \mathrm{~m}$ ) and one-quarter mile as spatial buffers to examine the spatial extent of drinking places on crime, Groff [4] identified the threshold at $366 \mathrm{~m}$ for the first bandwidth and $402 \mathrm{~m}$ for the second. She also stressed the importance of shorter bandwidths for better characterizing spatial extent because they provide a more complete picture of inner crime risk. In a recent study, Xu and Griffith [28] used smaller bandwidths, $1.7 \mathrm{~m}$, and found decreasing crime exposure levels in different distance intervals within a spatial extent of $304.8 \mathrm{~m}$.

In the extant literature, spatial extent is mainly measured by Euclidean distance [29,30] or street network distance [3,28]. Given that human movement between urban features is primarily constrained to street networks in urban settings, the former is less likely to fully represent actual distances between urban features and crime incidents. Furthermore, this may cause false-positive spatial associations [31,32] or oversmoothed crime clusters [33]. Having tested the interchangeability of Euclidean and network distance in an urban context, Maki and Okabe [34] found significant differences in their distance calculations under $400 \mathrm{~m}$. Similarly, Groff [4] tested the strength of association between bars and crime at different distance thresholds and found that the association by street distance was up to three times higher than the association by the Euclidean distance. Such distance-related differences threaten the validity of a spatial influence indicator. The studies using network distance are not, however, without their limitations. They sometimes represent crimes with relevant street segments [3], which may decrease the precision of distances between crime and urban features. For instance, the deviation in actual distance between a crime event at the edge and an urban feature at the center would be a half-length of the street segment when the crime is represented by the centroid of a street segment. To avoid such miscalculations, $\mathrm{Xu}$ and Griffiths [28] proposed a continuous network space and used exact locations of each urban feature and crime as the units of analysis. This approach undoubtedly helped to improve precision, hence the accuracy of the spatial influence analysis.

\subsection{Spatial Influence in an Environmental Backcloth}

Spatial influence is embedded in an environmental backcloth $[8,9]$ that can be viewed as a cross-product of the social environment, built environment, people, behavior, activities, and timing [35]. Within the context of urban crime, this backcloth underlines the roles of the built environment (i.e., urban features and street networks) and human activity in shaping crime opportunities around places. Being the primary medium of human movement, the built environment channels human activity to different sets of places during the day or the week, thus changing the crime opportunity landscape across a city. This temporal fluctuation in the activity levels across places is often explained by a time geography 
perspective: the spatiotemporal rhythm of urban life [12] imposes various constraints on individuals $[13,36]$ and limits their movements in space and time. For example, individuals must visit places (e.g., banks and grocery stores, etc.) within specified operating hours or weekdays to perform relevant tasks. This and many other similar limitations dictate that individuals, whether they be an offender or a target, must follow generic pathways between activity nodes (e.g., work, shop, home, and public transit, etc.). The increasing number of people who share the same pathways during their daily routines creates a cyclical crime opportunity pattern around urban features during the day [37] or during the week [38,39]. A body of research has thus far validated the existence of this temporality in crime opportunity around urban features such as schools, bus stops, and fast-food restaurants [37,40-42].

It should be noted that the spatial influence of urban features may not be stable across a city even for the same crime type [43]. A small portion of the same type of urban features often experience most of the crime, producing a j-shaped crime distribution across a city [10]. Kinney et al. [18] explained this heterogeneity with the concept of urban mosaic [11], wherein cities are viewed as an array of mosaics, each having differential urban layouts, activities, and sociodemographic levels. A body of research has thus far shown the role of urban mosaics in the spatiotemporal influence of urban features. In a recent study, Hipp and Kim [44] found that the risk of robbery significantly decreased in Southern California when employees in a commercial area were around in the daytime, whereas that effect did not exist at night. Additionally, they indicated an increased robbery risk on high restaurant segments in the early evening of weekends. In another study that focused on regional sociodemographic differences, Stucky and Ottensman [15] reported a negative relationship between social disadvantage and spatial influence of retail stores on robbery. In sum, the literature indicated the necessity for a crime-specific spatiotemporal approach in any spatial influence analysis with a reference to environmental backcloth.

The cyclical crime opportunity patterns vary across crime types given differences in situational factors. According to situational crime prevention principles, different crime types necessitate different security measures because they have different levels of associated crime opportunities [17]. For example, a car with an open window would pose different crime opportunities in terms of motor vehicle theft and robbery. Similarly, the crime opportunity level that a vacant home represents will be totally different for burglary than it is for an assault. This differential opportunity has some implications for spatial influence. In a remarkable study examining the spatial influence of different crime types in Philadelphia, PA, Groff and Lockwood [3] found that bars have nearly 1.5 times higher spatial influence on disorder crimes than they have on violent and property crime within a $120 \mathrm{~m}$ bandwidth. Similarly, a more recent study [45] indicated that assault density is two times higher than robbery density within a $100 \mathrm{~m}$ bandwidth from a school. This ratio, for the same pair of crime densities, is 1.5 times higher within the same bandwidth from a recreational hub. In sum, spatial influence operates differently for different types of crimes, underlining the need to develop crime-specific spatial influence indicators within a spatial extent.

\subsection{This Study}

In the current study, we conceptualized urban features as base stations broadcasting risk signals (i.e., spatial influence) with decreasing strength levels (i.e., distance decay effect) throughout a coverage area (i.e., spatial extent). To evaluate their signal performance under different configurations, we introduced a crime-specific spatiotemporal approach. To test this approach, we used a methodology that combines network $\mathrm{K}$ analysis with segmented regression. By using network $\mathrm{K}$ analysis, we first examined the crime clusters around urban features across street networks. Then, for significant clusters, we used segmented regression to model the spatial influence as a function of street network distance. A similar method was previously applied by $\mathrm{Xu}$ and Griffiths [28] in their examination of the spatial influence of urban features on gun violence in Newark, NJ. We extended this study to 
analyze spatiotemporal influences of a wide range of selected urban features on robbery and theft in Chicago, IL.

Determining a suitable spatial extent threshold is a challenging task given physical layout differences within and between cities. These differences often impede a comparative spatial influence analysis across different contexts. In a remarkable study, McCord and Ratcliffe [46] proposed the intensity value analysis (IVA) to calculate spatial influence through an inverse distance weighted (IDW) count measure within a given radial bandwidth. This approach allowed for the testing of differential spatial influence within and between urban features across periods, regions, and crime types. Motivated by this idea, we introduced distance-aware risk signal functions using a segmented regression technique. Before, this technique was applied by researchers to identify the change points marking where spatial influence significantly changed $[1,28]$. In our work, we used it to model the spatial influence within a given a spatial extent. Using these functions, we then developed two spatial influence indicators: risk signal intensity score (RSIS) and risk signal strength score (RSSS). The first indicates cumulative crime density within a given spatial extent, while the second represents the spatial diffusion effect by measuring the percentage change between an estimated local effect and the RSIS. As an illustrative example, for a crime density of two at the origin point (i.e., local effect) and a cumulative crime density of 1.5 (i.e., RSIS) at the spatial extent, the RSSS value is calculated as -33.3, indicating a one-third decrease in the spatial influence. After comparing these scores across various spatiotemporal models, a correlation analysis examined their relationship with one of the key sociodemographic characteristics: concentrated disadvantage.

In sum, this study contributes to the current literature in many ways. First, it uses network $\mathrm{K}$ analysis as a filter that eliminates the insignificant crime clusters around urban features. Second, instead of a single value, it alternatively proposes a risk signal function to model the spatial influence of an urban feature within a given spatial extent. Third, it introduces two novel spatial influence scores (i.e., RSIS and RSSS) and compares them across spatiotemporal models and crime types. Lastly, it quantifies the relationship between spatiotemporal influence and concentrated disadvantage through a correlation analysis.

\section{Materials and Methods}

\subsection{Study Setting}

Chicago is the third-largest city in the U.S., with a population of nearly 3 million. The city currently consists of 200 neighborhoods and 77 community areas [47]. Originally planned to have three main sides (i.e., north, west, and south) due to a natural boundary set by the Chicago River [48], as it grew larger, the city further evolved into nine sides: Center side (CS), Far North side (FNS), Far Southeast side (FSES), Far Southwest side (FSWS), North side (NS), Northwest side (NWS), South side (SS), Southwest side (SWS), and West side (WS). Each side is known to have some distinguishing regional characteristics. For instance, the CS is the attraction center of the city, hosting major corporate headquarters, shopping centers, and theaters, while the FNS is home to the most vibrant immigrant neighborhoods. On the other hand, neighborhoods with the highest disorder are located on the WS and SS. In contrast, the NS covers the wealthy areas accommodating the most affluent neighborhoods in the city $[49,50]$. Such differences also have implications in crime level. For instance, Block [51] reported that $55 \%$ of gang-related homicide and $35 \%$ of nonlethal gang-related offenses occurred on the WS. More recently, Schnell et al. [52] found that the main violent crime hotspots were located on the WS and SS of the city. These differences suggest the existence of localized crime risk patterns around urban features across these sides. Therefore, we selected the sides of Chicago as the spatial units of our spatiotemporal influence analysis. Figure 1 displays the sides and the related community areas of Chicago. 


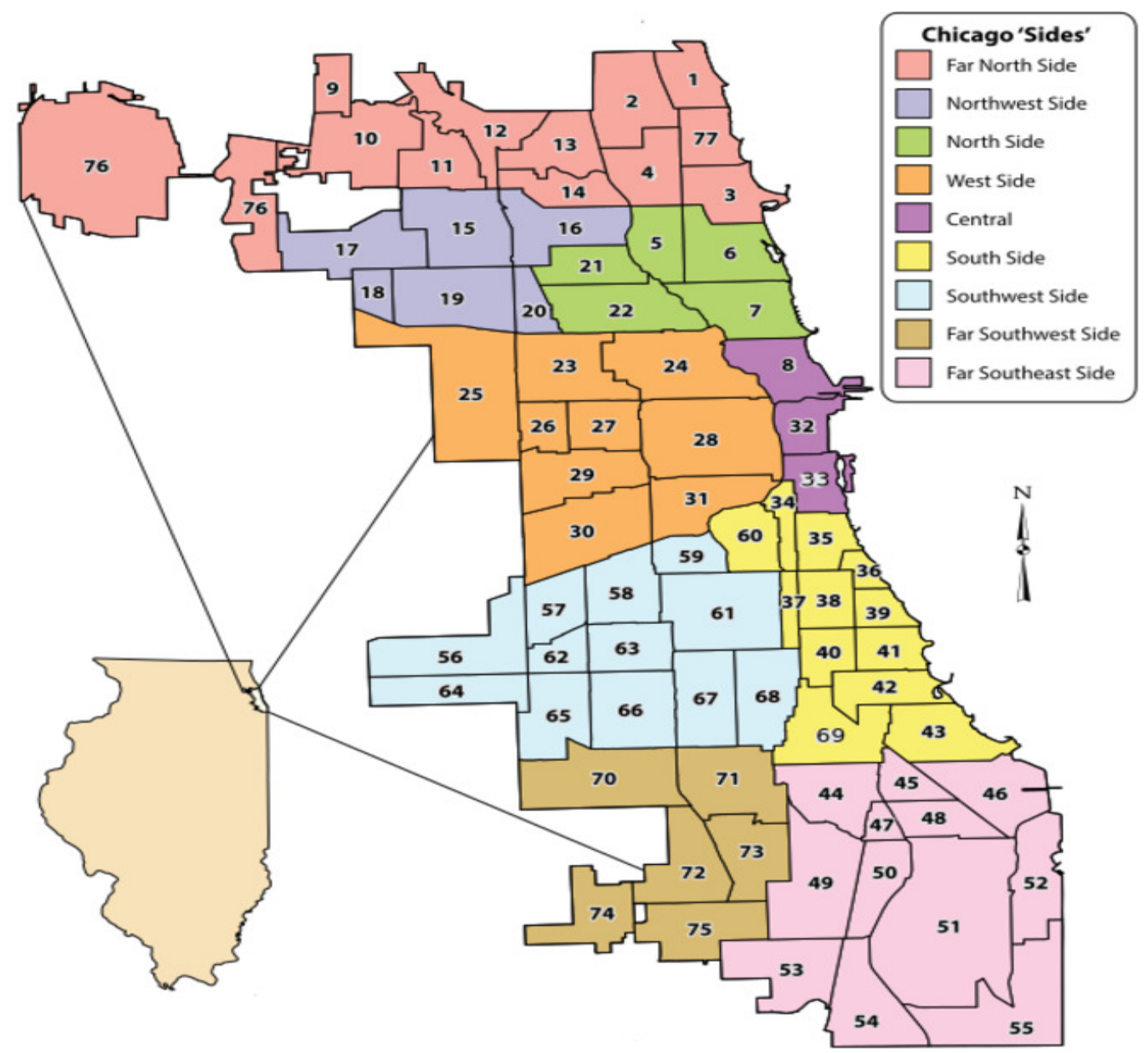

Figure 1. Main sides and corresponding community areas of Chicago (adapted from City of Chicago Data Portal).

\subsection{Creating Street Networks for the Sides of Chicago}

A street network can be formulated as an undirected graph: $G(V, E, W)$. Here, V (i.e., vertices) corresponds to a street intersection, $\mathrm{E}$ (i.e., edges) denotes a street segment between two intersections and W (i.e., weight) is the segment length. Based on this formulation, we firstly created a main graph from a street centerline shapefile. All the shapefiles were retrieved from the City of Chicago Open Data Portal (https://data.cityofchicago.org/, accessed on 4 July 2021). Each feature in this graph corresponds to a street segment with the following attributes: segment ID, object IDs, GPS coordinates of involved intersections, and length. We then spatially joined these street segments to the nearest community areas specified in community areas boundaries shapefile. Given each community area is only related to one side, segments were automatically mapped to relevant sides, creating separate networks. Street segments were spatially joined with the nearest community area by using NNQGIS plug-in of QGIS 3.6.0 Software. Then, we obtained a continuous network by excluding all the independent street segments that remained outside of the main component. To do this, we identified components of resulting side networks using spatstat package in $\mathrm{R}$ and excluded all the segments independent of the main component (i.e., comprised of the majority of street segments). We thus ensured the fully connected street networks for each side, which was instrumental because disconnected networks might complicate the results of any spatial analysis by deviating distance calculations [53]. The resulting networks are displayed in Figure 2. Descriptive information is summarized in Table 1. 


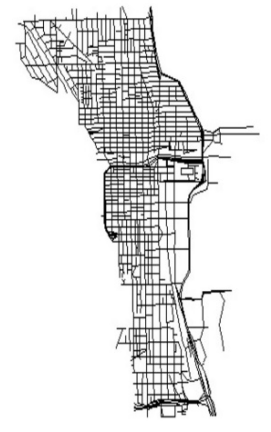

(a)

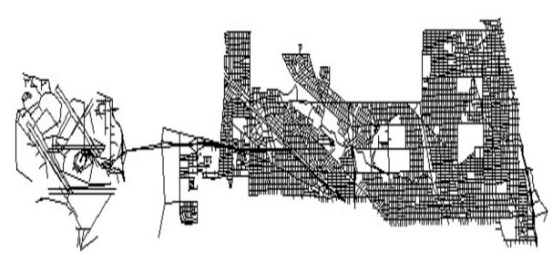

(c)

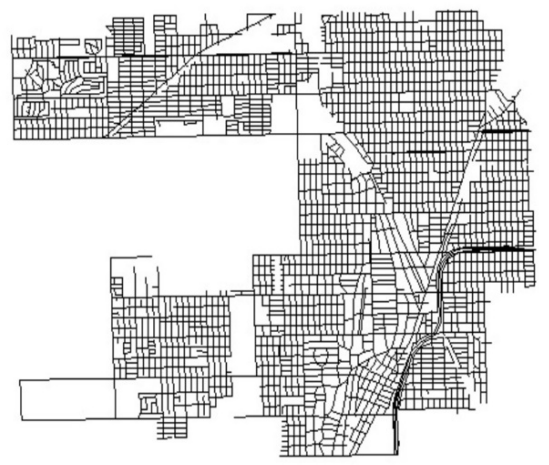

(e)

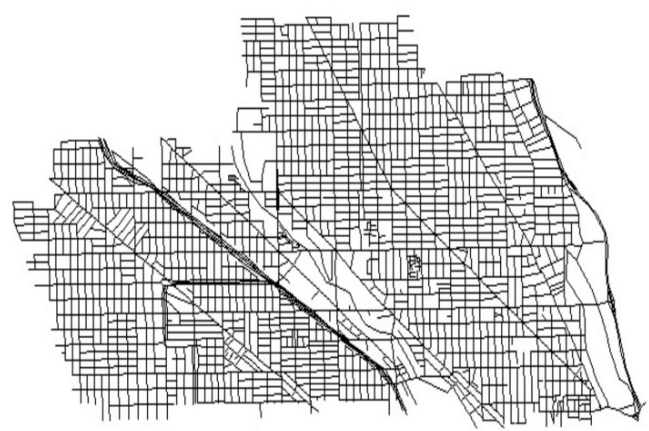

(g)

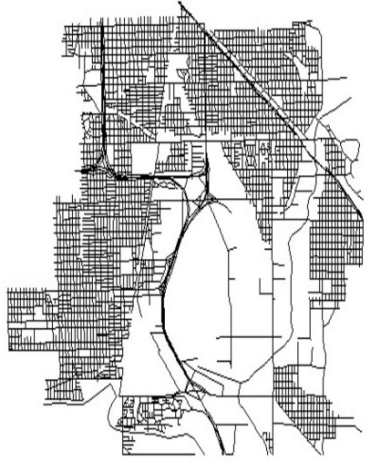

(b)

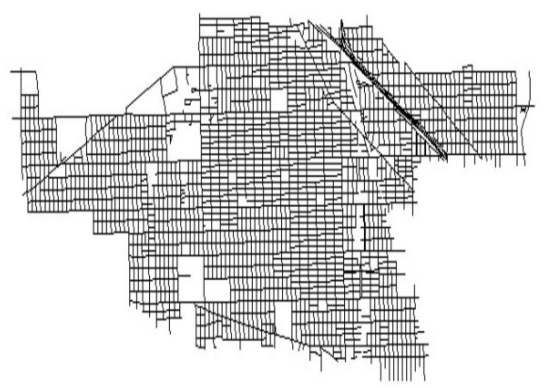

(d)

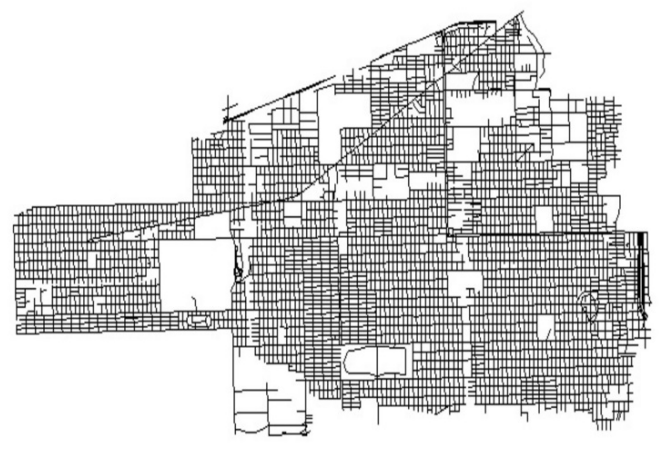

(f)

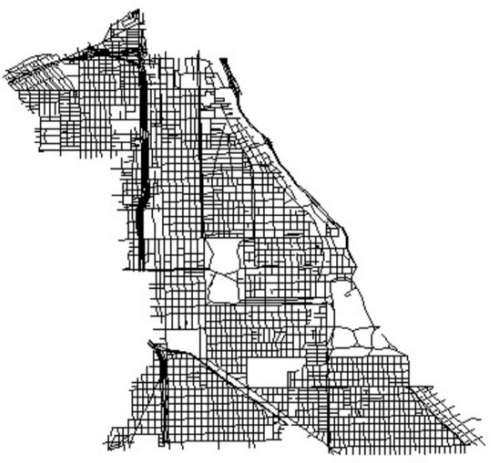

(h)

Figure 2. Cont. 


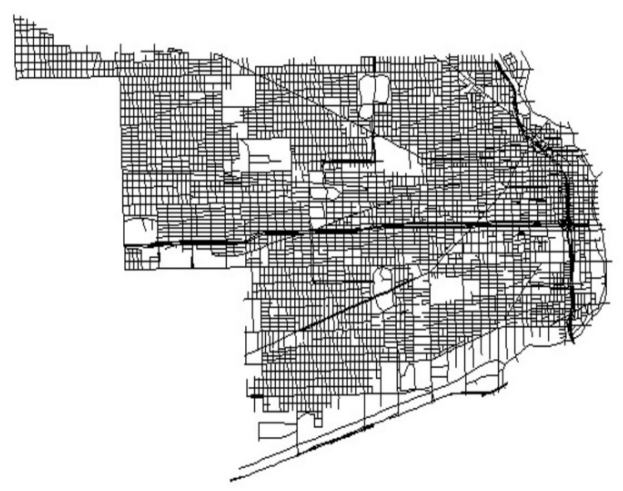

(i)

Figure 2. The side street networks (a) CS, (b) FSES, (c) FNS, (d) NWS, (e) FSWS, (f) SWS, (g) NS, (h) SS, and (i) WS.

Table 1. Subnetwork summaries.

\begin{tabular}{cccccc}
\hline Sides & \#Nodes & \#Edges & Bounding Box Coordinates & $\begin{array}{c}\text { Bounding } \\
\text { Radius (m) }\end{array}$ & $\begin{array}{c}\text { Network K Distance } \\
\text { Chunks (m) }\end{array}$ \\
\hline C & 1680 & 2444 & $(41.91,-87.60 ; 41.84,-87.65)$ & 9977.9 & 19.4 \\
FN & 5407 & 8151 & $(42.02,-87.63 ; 41.93,-87.93)$ & $29,611.9$ & 57.7 \\
FSE & 4873 & 7227 & $(41.75,-87.52 ; 41.64,-87.66)$ & $20,438.6$ & 39.8 \\
FSW & 3509 & 5308 & $(41.75,-87.63 ; 41.66,-87.74)$ & $15,932.5$ & 31.0 \\
N & 2691 & 4145 & $(41.96,-87.62 ; 41.91,-87.73)$ & $14,001.2$ & 27.2 \\
NW & 2693 & 4423 & $(41.96,-87.69 ; 41.91,-87.83)$ & $16,737.1$ & 32.6 \\
S & 4040 & 6023 & $(41.85,-87.54 ; 41.74,-87.66)$ & 15,770 & 30.7 \\
SW & 5032 & 7976 & $(41.78,-87.62 ; 41.75,-87.80)$ & $17,380.9$ & 33.8 \\
W & 6762 & 10,395 & $(41.92,-87.63 ; 41.81,-87.80)$ & $20,760.5$ & 40.4 \\
\hline
\end{tabular}

\subsection{Crime Dataset}

The Chicago crime dataset consists of all criminal incidents from 2001 to the present. Each row in this dataset represents a crime incident with 22 attributes including crime ID, date-time, $\mathrm{x}$ and $\mathrm{y}$ coordinates, the primary description of the crime, the neighborhood, and the community area. Our sample consisted of theft $(n=64,024)$ and robbery $(n=9685)$ incidents in 2018. The Chicago crime dataset was retrieved from the City of Chicago Open Data Portal (https:/ / data.cityofchicago.org/, accessed on 4 July 2021). To examine the spatiotemporal influence analysis, we aggregated crimes at sides and at three separate temporal levels: default, intraday, and weekly. In the first level, we matched each incident with relevant side street networks in the community area field without any time differentiation (default). In the second level, the incidents were assigned to one of three equal shifts during a day, the first shift (FS) from 00:00 to 07:59, the second shift (SS) from 08:00 to 15:59, and the third shift (TS) from 16:00 to 23:59, based on the hour of occurrence. These shifts were defined based on the working watches of Chicago police officers [54]. In the last level, we used a weekend (WE) and weekday (WD) division to group incidents: the weekend covered all incidents between the third shift of Friday and the first shift of Monday (excluded), and the remaining incidents were included on weekdays. This procedure generated a total of 54 spatiotemporal models ( 9 default $+9 \times 3$ intraday levels $+9 \times 2$ weekly levels). Robbery and theft distributions across these models are displayed in Figure 3. 


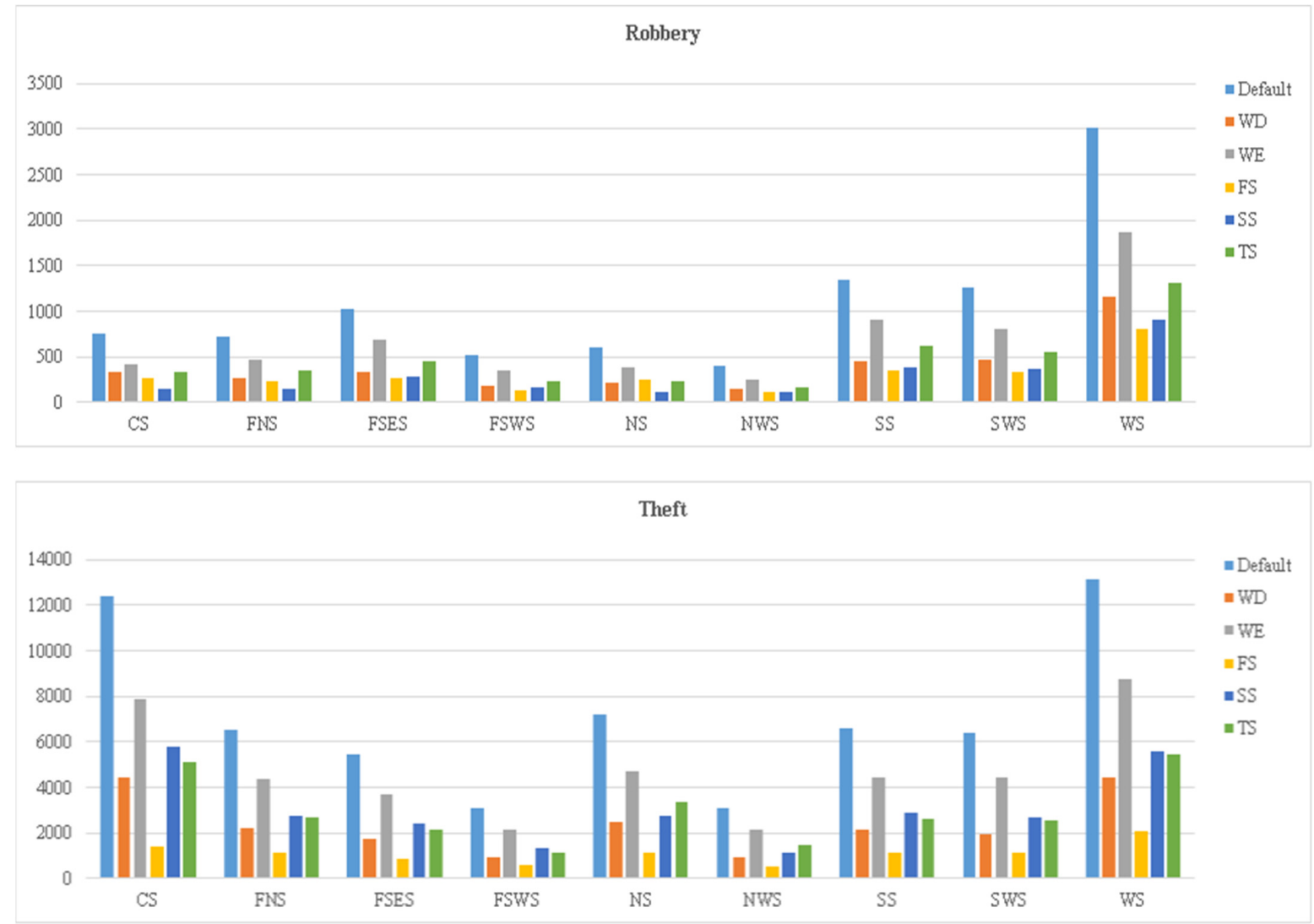

Figure 3. Spatiotemporal distribution of crime incidents.

\subsection{Urban Features}

The locations of commercial features were retrieved from the Chicago business licenses dataset. With the guidance of business activity definitions for each record, we obtained unique instances of fast-food restaurants, pubs, grocery stores, and gas station records. For bus stops, the locations were retrieved from the CTA bus stops shapefile. The final dataset included fast-food restaurants $(n=402)$, grocery stores $(n=1330)$, gas stations $(n=350)$, pubs $(n=810)$, and bus stops $(n=10900)$, for which significant influences were reported in Chicago studies $[30,38,43,55,56]$. The distribution of these features across the sides of Chicago is displayed in Figure 4.

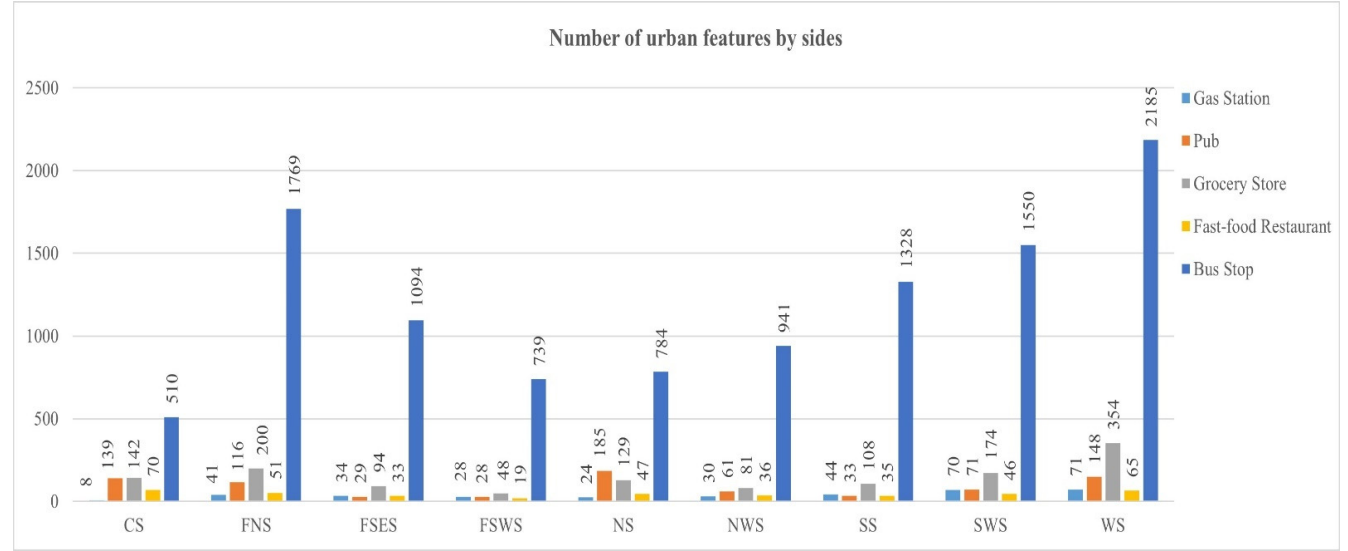

Figure 4. Number of selected urban features by side. 


\subsection{Concentrated Disadvantage (CD)}

Concentrated disadvantage $(\mathrm{CD})$ is one of the major indicators of social disorganization in a neighborhood, and it was repeatedly found to have a significant impact on the spatial influence of urban features [15]. In this study, we measured the CD with four indicators: the percentage under 15 and above 64 years of age, the percentage of unemployed residents, the percentage of households below the poverty line, and the median income. The data were not available at the side level. We, therefore, had to use a weighted apportioning method [57] to impute the side-level CD data. For each side, we calculated an average $C D$ that was weighted by the population of the related community areas. The descriptive statistics for side CD are displayed in Table 2.

Table 2. Side descriptive statistics for the selected variables.

\begin{tabular}{|c|c|c|c|c|c|}
\hline & Mean & SD & $\begin{array}{l}\text { Eigen } \\
\text { Value }\end{array}$ & $\begin{array}{c}\text { Factor } \\
\text { Loadings }\end{array}$ & $\begin{array}{c}\text { Cronbach's } \\
\text { Alpha }\end{array}$ \\
\hline Concentrated Disadvantage (CD) & 0.000 & 1 & 3.105 & & 0.901 \\
\hline \% under 15 above 64 years & 38.074 & 6.545 & & 0.753 & \\
\hline$\%$ unemployed & 5.973 & 3.075 & & 0.907 & \\
\hline$\%$ less than poverty & 29.936 & 13.964 & & 0.925 & \\
\hline Inverted median income & $51,038.798$ & $23,754.78$ & & 0.926 & \\
\hline
\end{tabular}

\subsection{Network K Function}

Network K function [58] is an extension of the ordinary $\mathrm{K}$ function, which summarizes a point pattern, tests hypotheses about the pattern, and estimates parameters and fit models [59]. This function operates on a finite irregular network with the shortest-path distance, rather than a homogenous infinite plane with the Euclidean distance. In this study, we use a bivariate network cross $\mathrm{K}$ function to examine whether the locations of urban features influenced the spatial distribution of crime. This function allowed for the analysis of crime clustering within a given distance. Theoretically, it can be formulated as:

$$
K^{b a}(t)=\frac{1}{\rho_{a}} E\left(t h e \text { number of points A within network distance } t \text { of a point } b_{i} \text { in } B\right)
$$

where $\mathbf{E}($.$) denotes the expected value with respect to b_{i}, \ldots b_{n}\left(b_{i} \in B\right)$, which follows a binomial point process, and $\rho_{\mathbf{a}}$ is the density of points $\mathrm{a}, \boldsymbol{\rho}_{\mathbf{a}}=\frac{\mathbf{n}_{\mathbf{a}}}{\left|\mathbf{L}_{\mathbf{T}}\right|}(2)$. Here, $\left|\mathbf{L}_{\mathbf{T}}\right|$ denotes the total length of the line segments in a network. For observed point processes of different types, the observed network cross $\mathrm{K}$ function of $\mathrm{A}$ (i.e., crime) relative to $\mathrm{B}$ (i.e., urban feature) can be formulated as:

$$
\hat{\mathbf{K}}^{\mathbf{b a}}(\mathbf{t})=\frac{\left|\mathbf{L}_{\mathbf{T}}\right|}{\mathbf{n}_{\mathbf{a}} \mathbf{n}_{\mathbf{b}}} \sum_{\mathbf{i}=1}^{\mathbf{n}_{\mathbf{b}}}\left(\text { the number of points of } A \text { on } \mathbf{L}_{\mathbf{b}_{\mathbf{i}}}(\mathbf{t})\right)
$$

Here, if $\hat{\mathbf{K}}^{\mathbf{b a}}(\mathbf{t})>\mathbf{K}^{\mathbf{b a}}(\mathbf{t})$, then it can be concluded that a is clustered around $\mathbf{b}$, otherwise, if $\hat{\mathbf{K}}^{\mathbf{b a}}(\mathbf{t})<\mathbf{K}^{\mathbf{b a}}(\mathbf{t})$, then it can be concluded that a is dispersed around $\mathrm{b}$. The comparison of $\mathbf{K}^{\mathbf{b a}}$ and $\hat{\mathbf{K}}^{\mathbf{b a}}$ invokes the calculation of the expectation in (1), that can be analytically evaluated through the complete spatial randomness (CSR) hypothesis. This CSR hypothesis posits that the different types of points are independently and identically distributed according to the binomial distribution over network space. In this study, we tested CSR with a Monte Carlo simulation that generated 39 complete spatial random point patterns for crimes and urban features on a network, $\mathbf{L}_{\mathbf{T}}$. For each simulated pattern, the number of crime incidents on distance $t$ from an urban feature were calculated on a network. The minimum and maximum values at distance $t$, obtained from these simulated point patterns, are the critical upper and lower values at the $\alpha=0.05$ significance level [60]. If the observed count of crimes exceeded the upper value, we could assume a significant clustering; if it was below the lower value, we could assume a significant dispersion, otherwise, the relationship was insignificant. We ran separate network $\mathrm{K}$ analysis for each 
of 54 spatiotemporal models on the spatstat package [61] on $\mathrm{R}$ for evaluating the clustering of crime incidents around urban features. The Monte Carlo simulation helped to eliminate all the insignificant spatial influences before risk signal functions analysis.

\subsection{Risk Signal Functions, RSIS and RSSS}

Segmented regression is a type of regression analysis that is well-suited for modeling the changing relationships between an independent $(x)$ and a dependent variable $(y)$ in different intervals of $x$. This analysis identifies the $x$ values, marking change points where estimated coefficients of the regression equation significantly differ between intervals. This equation is formulated as:

$$
\mathbf{E}[\mathbf{y} \mid \mathbf{x}]=\boldsymbol{\beta}_{0}+\boldsymbol{\beta}_{1} \mathbf{x}+\boldsymbol{\delta}_{1}\left(\mathbf{x}-\boldsymbol{\tau}_{1}\right)^{+}+\ldots+\boldsymbol{\delta}_{\mathbf{k}}\left(\mathbf{x}-\boldsymbol{\tau}_{\mathbf{k}}\right)^{+}
$$

where $\tau_{\mathbf{k}}$ represents unknown changepoints whereby $\left(\mathbf{x}_{\mathbf{i}}-\boldsymbol{\tau}_{\mathbf{k}}\right)^{+}=\left(\mathbf{x}_{\mathbf{i}}-\boldsymbol{\tau}_{\mathbf{k}}\right)$ if $\left(\mathbf{x}_{\mathbf{i}}-\boldsymbol{\tau}_{\mathbf{k}}\right)>0$. $\boldsymbol{\beta}_{0}, \boldsymbol{\beta}_{1}, \boldsymbol{\delta}_{1} \ldots \delta_{\mathrm{k}}$ are coefficients that were estimated by a permutation test method [62].

In this study, each observation $\left(\mathrm{x}_{\mathrm{i}}, \mathrm{y}_{\mathrm{i}}\right)$ consisted of a network distance and a corresponding cumulative crime density. The linear $\mathrm{K}$ cross function that we used for network $\mathrm{K}$ analysis outputs expected number of events at 513 equal points, marking equal distances within a bounding radius (i.e., maximum shortest path distance between any two points in a linear network). The bounding coordinates, radius, and distance chunks corresponding to the distance between these 513 points are reported in Table 1 . To estimate the segmented regression models, we used an adequate number from these observations that cover at least $400 \mathrm{~m}$ in a side network. For example, we used 21 observations for the center subnetwork with a chunk distance of $19.4(19.4 \times 21=407.4 \mathrm{~m})$ and 10 observations for the West side $(40.4 \times 10=404 \mathrm{~m})$ with a chunk distance of $40.4 \mathrm{~m}$. To create risk signal functions, we estimated segmented regression equations using Joinpoint Regression program to model crime density as a linear function of network distance (i.e., spatial influence) within a spatial extent. A sample risk signal function is displayed in Figure 5. We evaluated the performance of risk functions with RMSE and MAE.

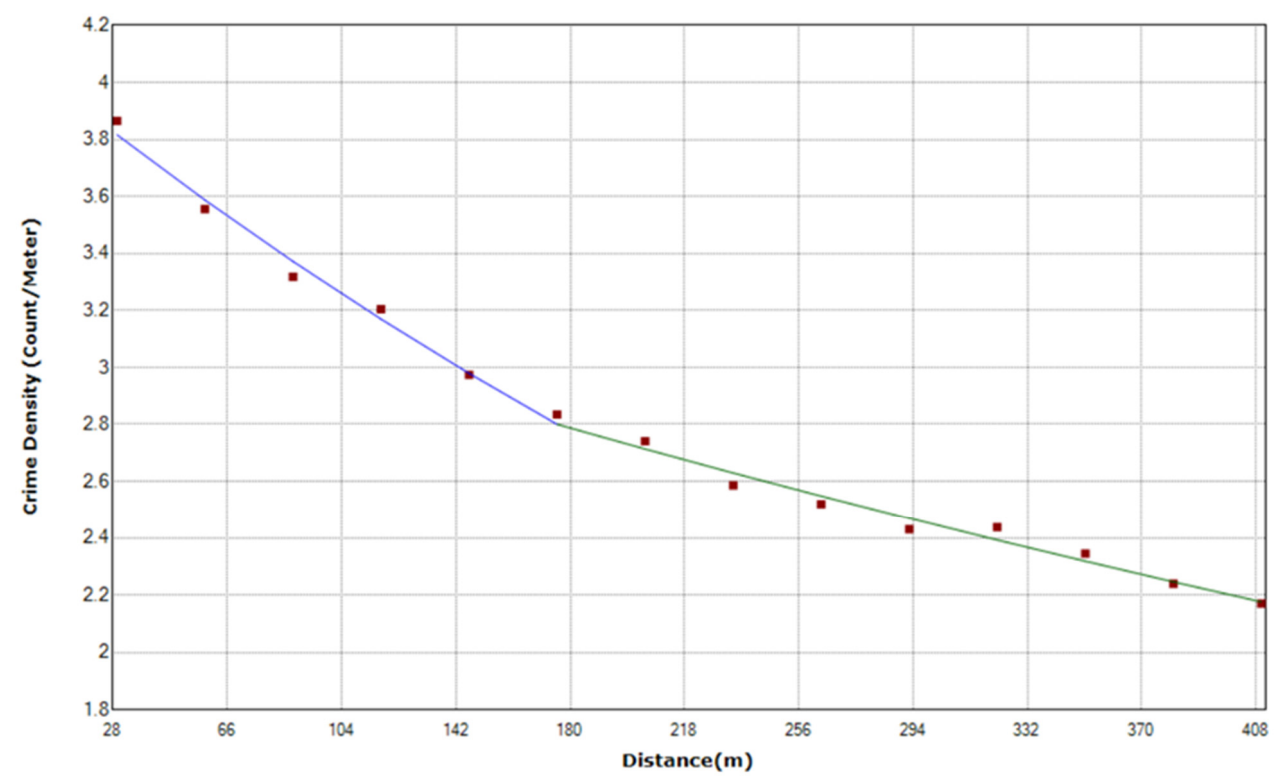

Figure 5. An illustration of a risk function.

From these functions, we derived RSIS and RSSS. RSIS is the estimated cumulative crime density at a given spatial extent. In this study, we selected $402.4 \mathrm{~m}$, a quarter-mile bandwidth, as the extent. This bandwidth was originally proposed in transportation research as a threshold for the maximum distance people would walk to get to the nearest public transport stations [63]. It was then adapted to the field of spatial crime research 
to draw the boundaries for the possible spatial interactions between urban features and crime [4].

A body of research has thus far used this value as a proxy for a spatial extent $[24,41,64,65]$. RSSS can be calculated by the following formula:

$$
\mathbf{R S S S}=\frac{\mathbf{R S I S}-\mathbf{E}[\mathbf{y} \mid \text { Origin }]}{\mathbf{E}[\mathbf{y} \mid \text { Origin }]} * 100
$$

Here, $\mathbf{E}[\mathbf{y} \mid$ Origin $]$ quantifies the local effect with the expected crime density at 5.5 feet $(1.7 \mathrm{~m})(\mathbf{E}[\mathbf{y} \mid 1.7])$ because crime incidents at the exact locations are sometimes geocoded with nearby areas for identification purposes [1]. RSSS can then be translated as the change percentage in local effect throughout a spatial extent, indicating a spatial diffusion effect. The value interval for RSSS is $(-\infty, \infty)$. It takes negative values in the case of distance decay and positive values for the urban features that have an increased spatial diffusion effect. We impute zeros into RSIS and RSSS values of the urban features that were found to have an insignificant spatial influence by bivariate network $\mathrm{K}$ analysis. This is because an insignificant clustering under the CSR hypothesis indicates that the observed crime clusters around an urban feature are merely chance products.

\subsection{Analytical Procedure}

The analysis started with the geocoding of urban features and crimes to the side street networks. The crimes were then aggregated at 54 spatiotemporal models. Next, we examined the significance of crime clustering around selected urban features in each model by using a network cross $\mathrm{K}$ analysis and a Monte Carlo simulation with 39 steps. After eliminating insignificant spatiotemporal clusters, we fitted a distance-aware risk signal function for each model in the form of estimated segmented regression equations. Using these functions, we derived RSIS and RSSS for each urban feature in selected crime types for each model. We applied nonparametric statistical tests (i.e., Wilcoxon signed rank and Kruskal-Wallis test) to examine the differences between these values across the models. Lastly, we analyzed the relationships between RSIS and RSSS values and CD through a correlation analysis.

\section{Results}

\subsection{Network K Analysis}

The network K results (Appendix A) confirmed the majority (509/540) of the hypothesized spatiotemporal crime clusters. Moreover, they revealed the differential spatiotemporal influences of gas stations, grocery stores, and pubs, on robbery and theft risk. Figures 6-8 exemplified one of these inconsistent clusters that were identified between pubs and robbery in the FSWS.

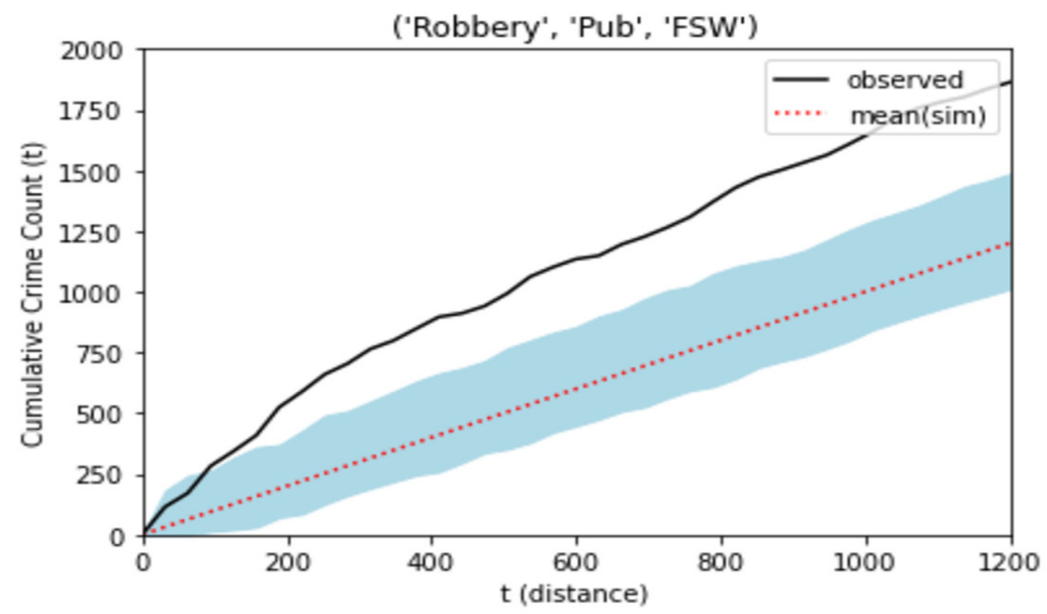

Figure 6. Network K result for robbery and pubs in FSWS. 


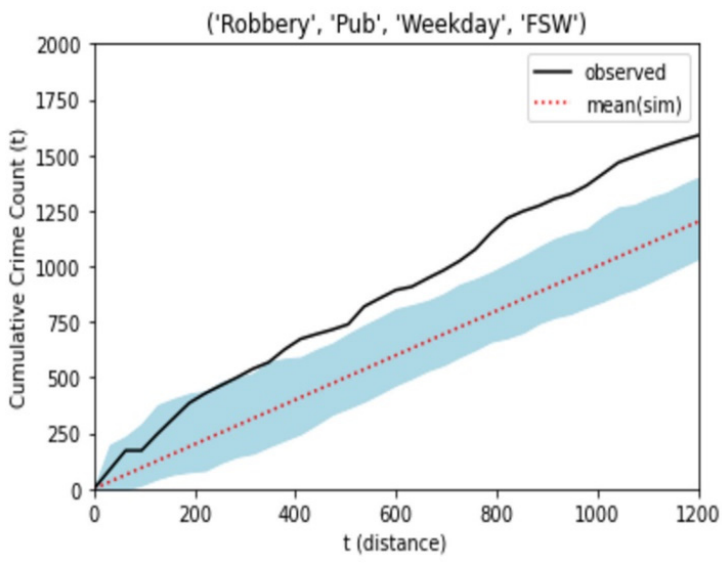

(a)

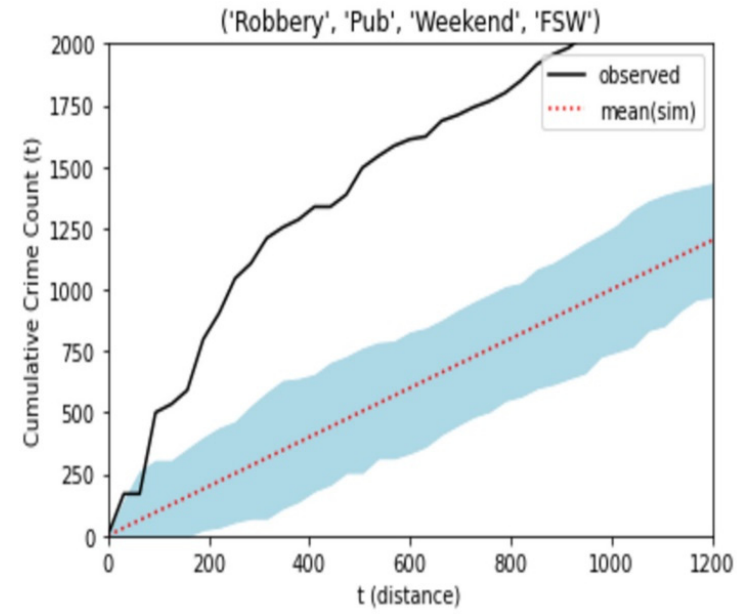

(b)

Figure 7. Network K results for robbery and pubs in FSWS during the (a) weekday and (b) weekend.

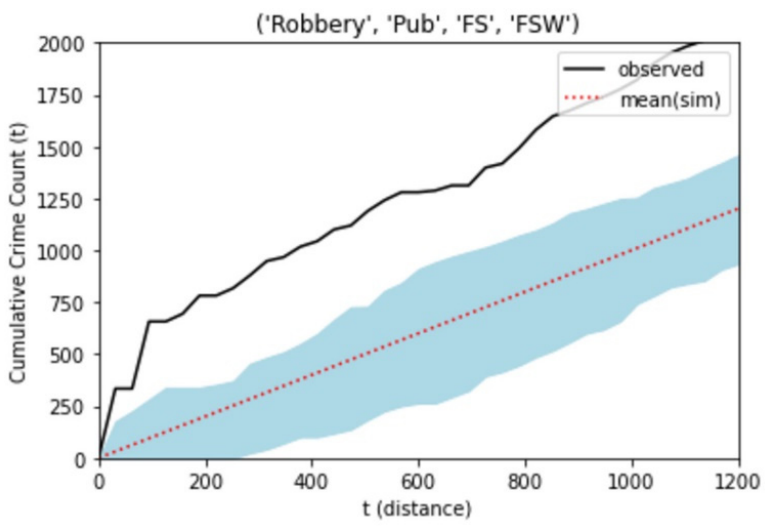

(a)

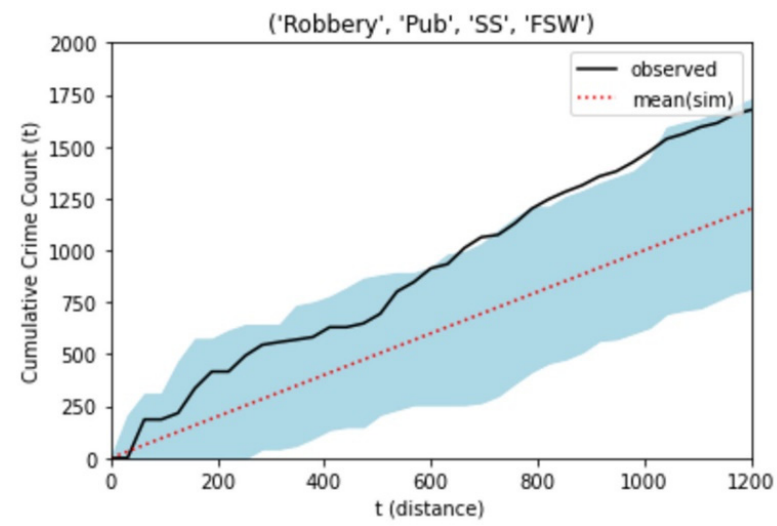

(b)

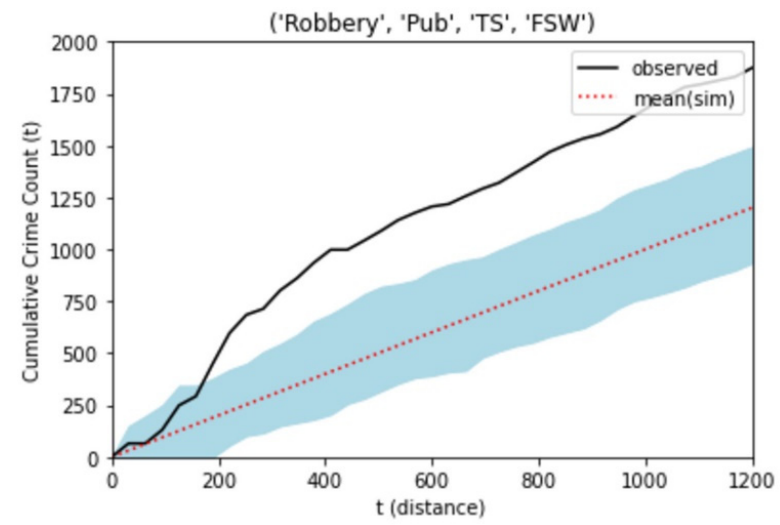

(c)

Figure 8. Network K result for robbery and pubs in FSWS during the (a) first shift, (b) second shift, and (c) third shift.

These figures illustrate the observed cumulative robbery counts at all distances from a pub up to $1200 \mathrm{~m}$. Figure 6 shows that the observed robbery count, represented by the continuous black line, is greater than the count that was obtained under the CSR hypothesis after nearly $100 \mathrm{~m}$. Here, the gray band demarcates the insignificance area where the observed count falls between the maximum and minimum values obtained from the Monte Carlo simulation. The dashed red line in the middle of the band represents the mean value of 39 simulations for each point. In sum, a continuous black line running above the gray band indicates a significant clustering, within the gray band indicates 
an insignificant clustering, and below the gray band indicates a significant dispersion. Figure 6, therefore, shows significant robbery clusters around pubs in the default model.

We observed no significant robbery and theft clusters within a quarter of a mile of gas stations on the CS in the default model.

The weekly model also indicated the differential spatial influence of gas stations on robbery and theft. While its influence on the robbery was not significant on the NS on both weekdays and weekends, the same existed only on the weekends in the CS. Further inconsistencies were also observed between pub and robbery in weekly models. Pubs did not attract robbery crimes on the SS and SWS during the weekend, nor did they on the FSWS and WS during weekdays.

Intraday models revealed many nuanced spatial influences. For instance, grocery stores on NWS and pubs on the SS and SWS did not attract robberies during the first shift. Similarly, there were no significant robbery clusters around gas stations on the CS, FNS, and NS during the second shift.

There were not any significant robbery clusters around gas stations on the CS and NS in the third shift. Spatiotemporal theft clusters around urban features, on the other hand, were more stable than robbery clusters. Only a few insignificant theft clusters were observed around gas stations across the CS and NS during all shifts.

\subsection{Spatiotemporal Influence Analysis}

As overall performance indicators of the fitted risk functions $(n=509)$, the mean MAE and RMSE values were found to be 0.119 and 0.13675 , respectively. Spatiotemporal influence analysis revealed significant differences in RSIS and RSSS across different crime types (Appendix B).

Figure 9 displays the RSIS and RSSS values of the bus stop in robbery and theft incidents across spatiotemporal models. The results of the Wilcoxon signed rank test indicated that theft RSIS of bus stops in the default model was significantly increased in the second shift ( $p$-value $<0.01)$ and decreased in the first shift ( $p$-value $<0.05)$. It also indicated a higher robbery RSIS during the first shift ( $p$-value $<0.05)$. We observed significantly higher RSSS of theft than that of robbery in the first shift. The Kruskal-Wallis test showed a lower RSIS of theft and robbery than that of fast-food restaurants and grocery stores in general. This relationship was reversed for RSSS values, as bus stops mostly had positive RSSS values. The tests revealed a significantly higher theft and robbery RSISs of bus stops located in the FNS, FSES, and FSWS. For RSSS, bus stops were found to have the lowest values in both crime types in the CS and NS.

Spatiotemporal theft and robbery RSIS and RSSS of fast-food restaurants are displayed in Figure 10. The main results indicated that both theft and robbery RSIS in the default model is significantly higher than first shift models ( $p$-value $<0.01$ ). A Kruskal-Wallis test for intraday differences further revealed significantly lower theft intensity around fastfood restaurants in the first shift than those calculated in other shifts $(p$-value $<0.01)$. We observed significant RSSS differences for robbery between default and weekday ( $p$-value $<0.05$ ), and between weekend and weekday models ( $p$-value $<0.01)$. The results further showed that the robbery intensity of fast-food restaurants was significantly higher than that of pubs during the second and third shifts. For theft, fast-food restaurants had higher intensity values than gas stations and pubs in all temporal models, except for the first shift model. The tests revealed significantly higher robbery RSISs of fast-food restaurants located in the FNS, FSES, and FSWS. For theft incidents, significantly higher values were mostly reported on the FSES. For RSSS, the CS and FE sides were found to have relatively greater values. 


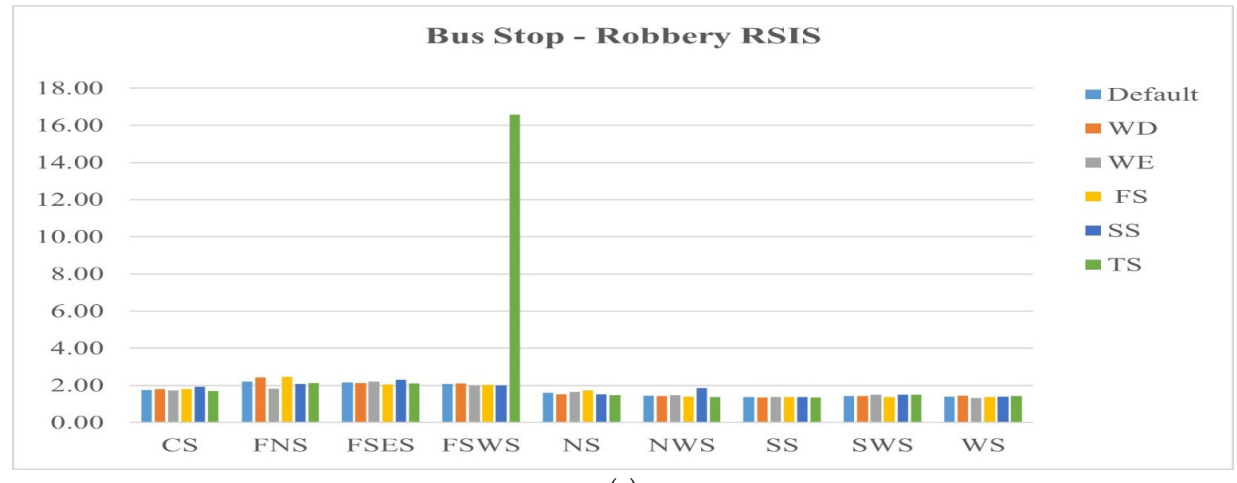

(a)

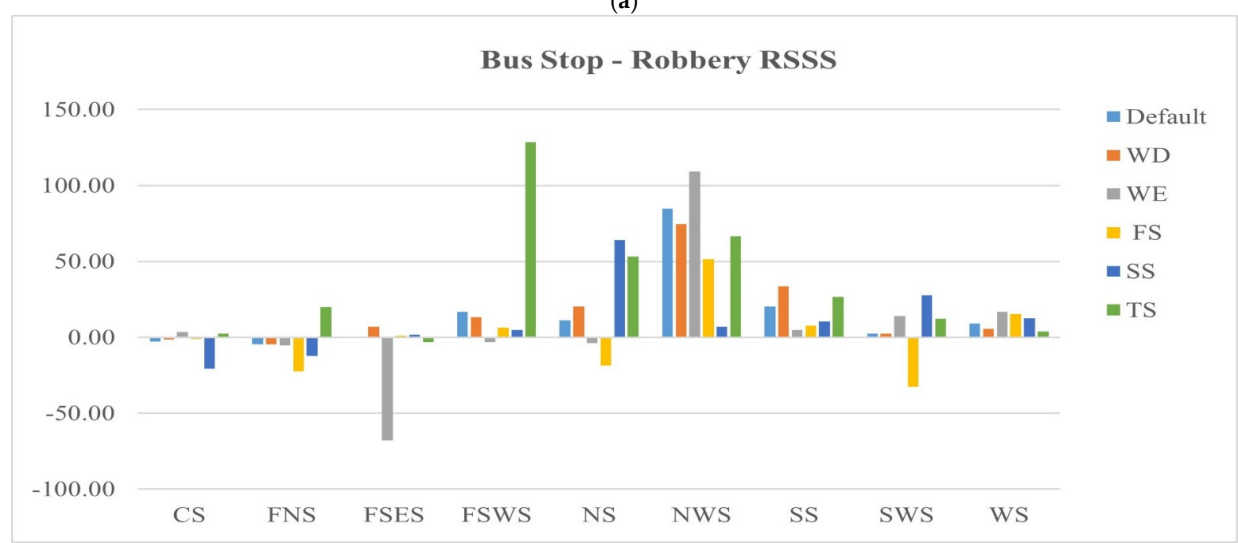

(b)

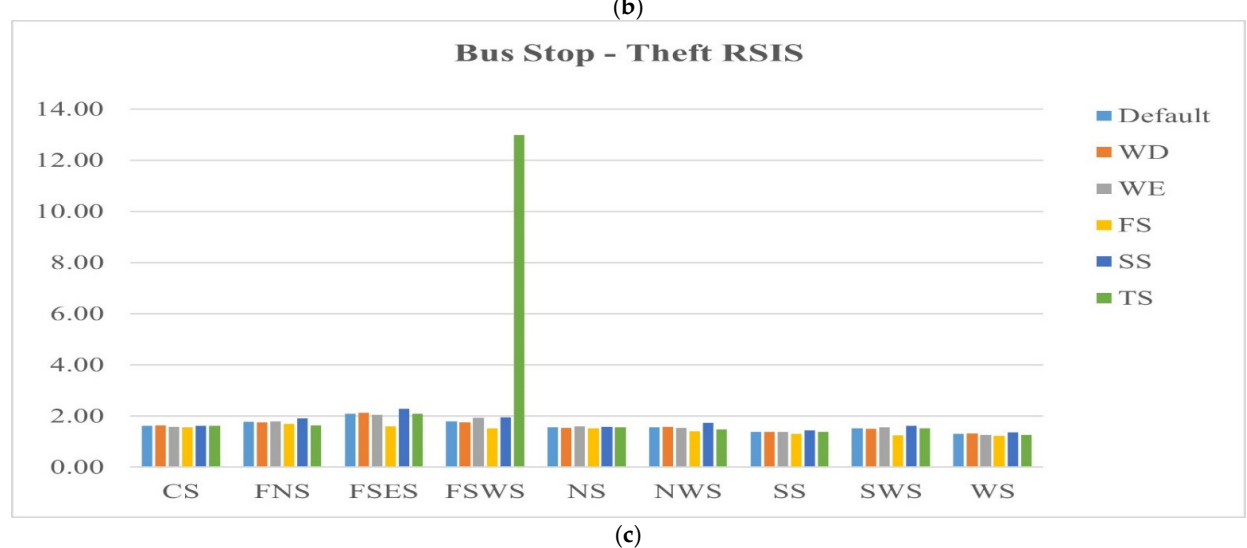

(c)

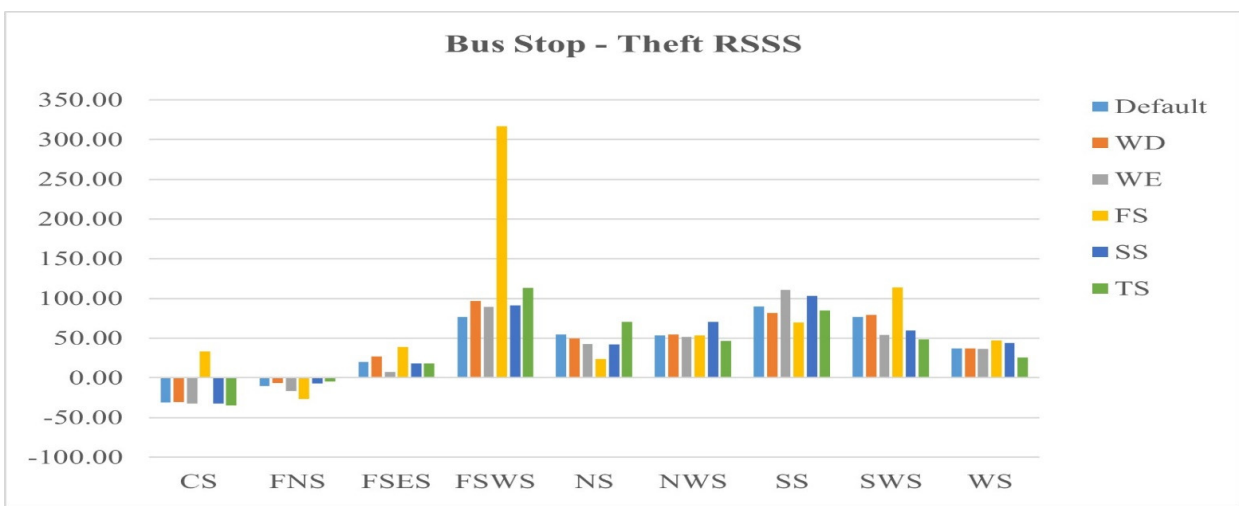

(d)

Figure 9. Bus stops RSIS on (a) robbery and (c) theft, and their RSSS on (b) robbery and (d) theft across spatiotemporal models. 


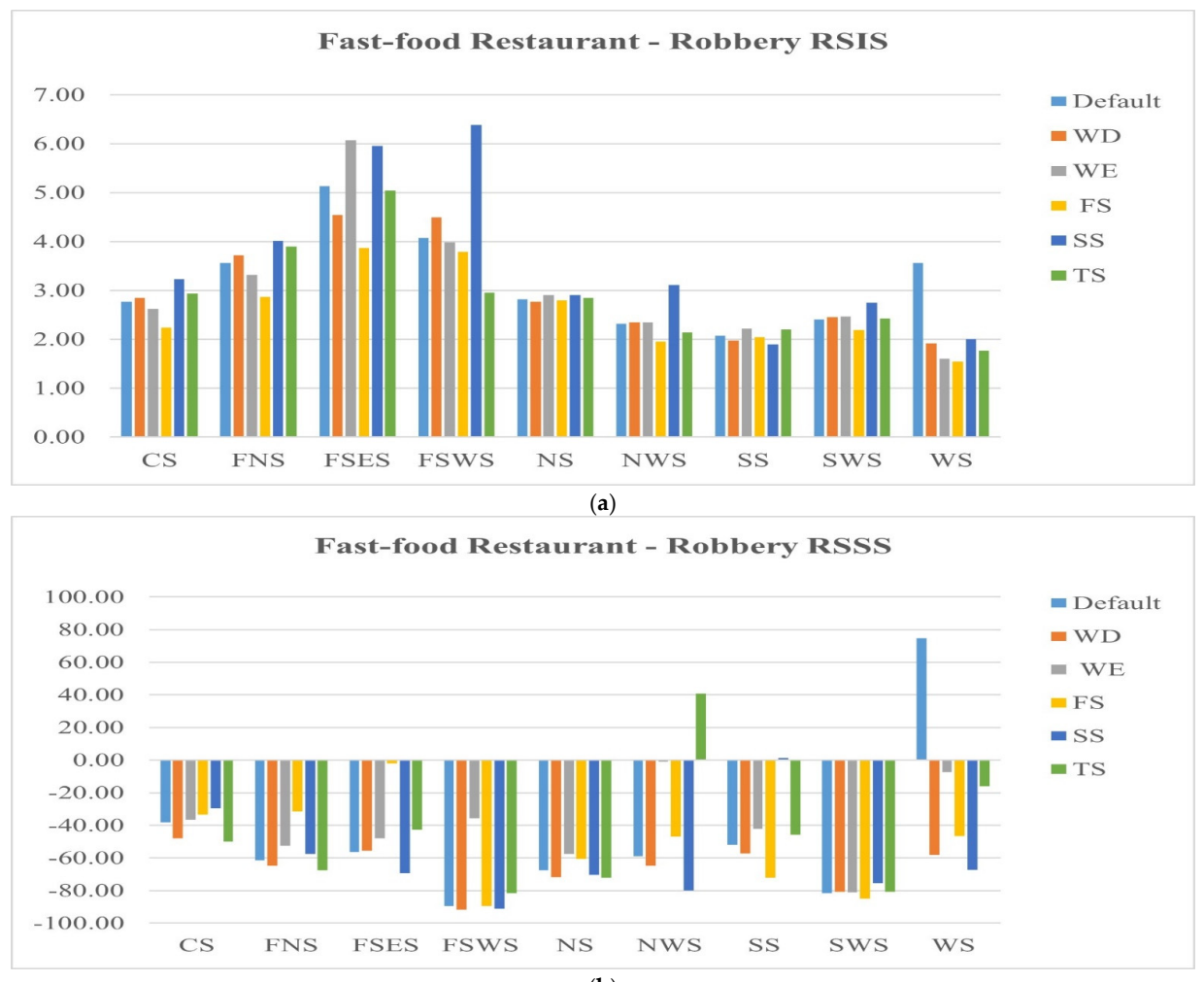

(b)

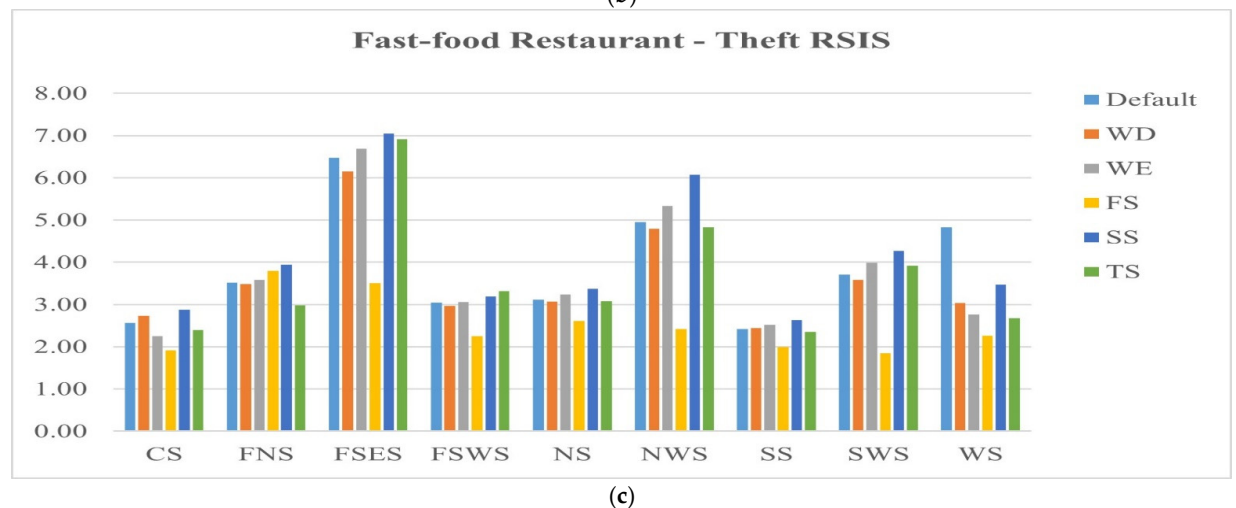

(c)

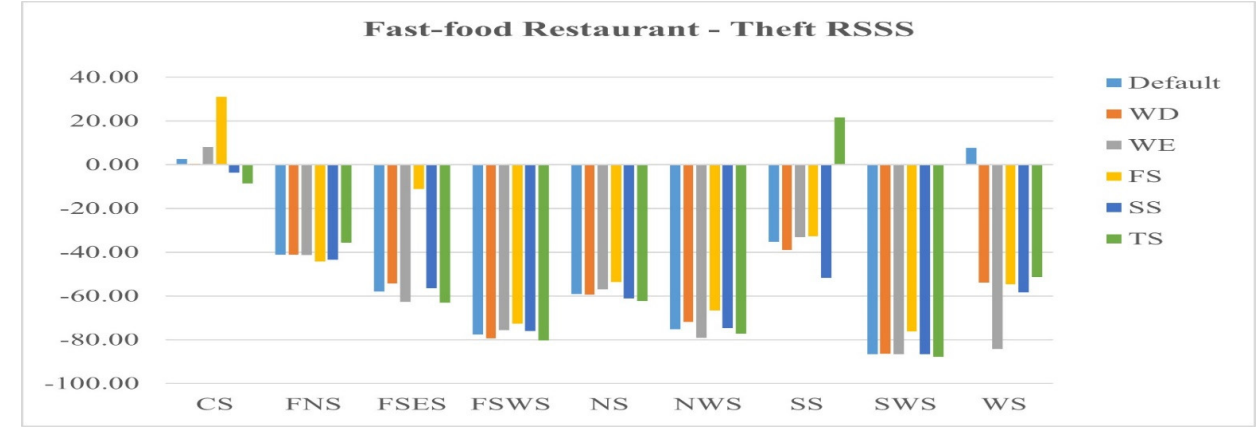

(d)

Figure 10. Fast-food restaurants RSIS on (a) robbery and (c) theft RSIS, and their RSSS on (b) robbery and (d) theft RSSS across spatiotemporal model.

The analysis results of gas stations are displayed in Figure 11. The Wilcoxon signed rank test indicated that robbery RSIS was significantly higher on weekends when compared to theft values $(p$-value $<0.05)$. We also found higher robbery RSSSs on weekdays. A comparative analysis with other features showed significant theft intensity differences between gas stations and fast-food restaurants across all temporal models. For RSSS, this 
difference was significant in robbery across the default, weekday, and second shift model. Further tests revealed a significantly higher robbery intensity around gas stations on the FSES and FSWS sides, as well as higher theft intensity in FSES, FSWS, and SWS. For theft RSSS, the SWS was consistently found to have the smallest values.
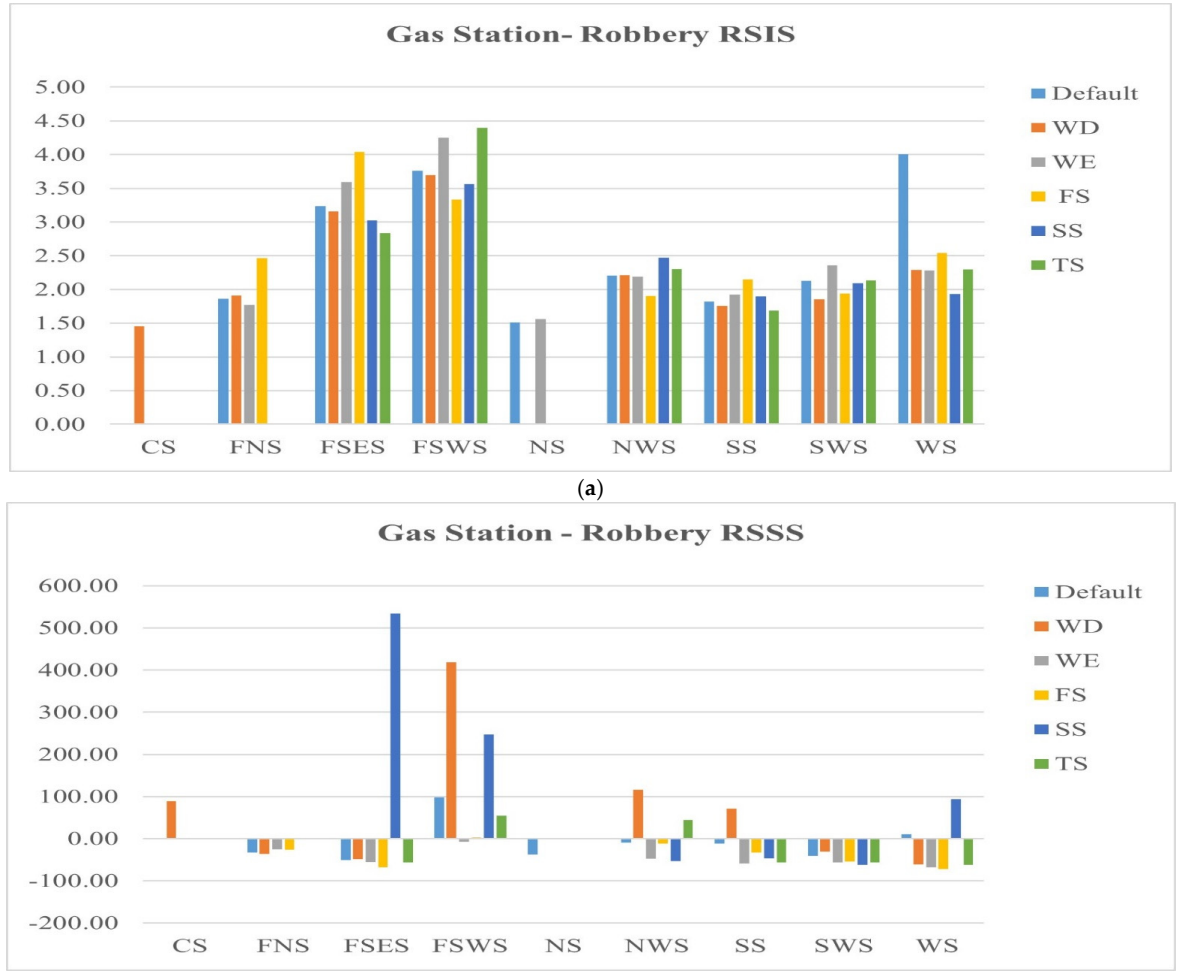

(b)

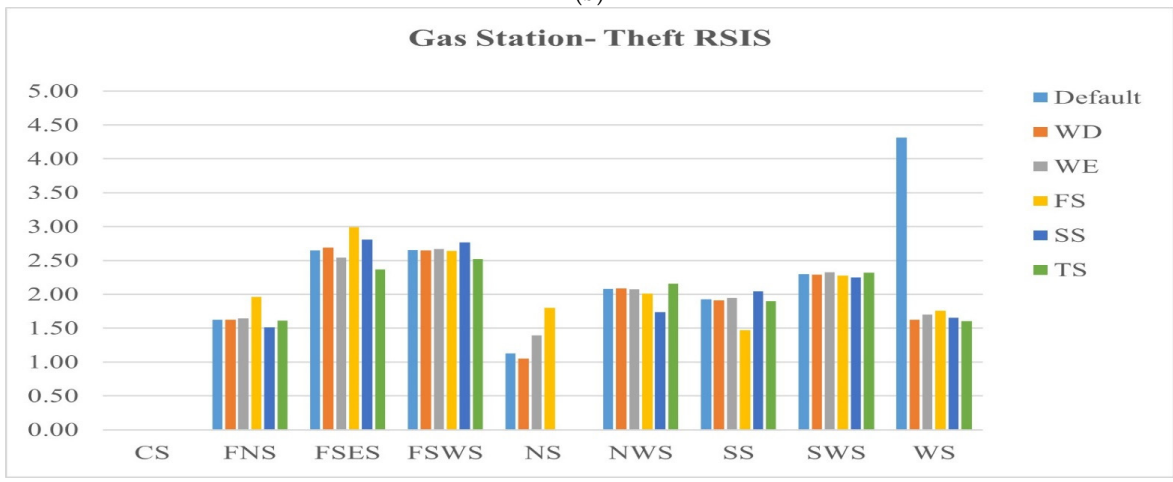

(c)

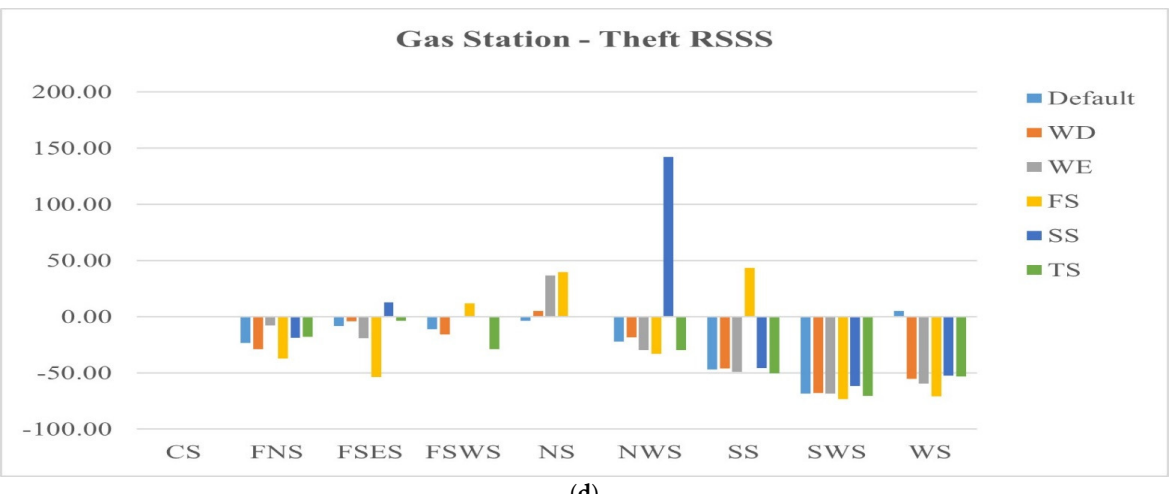

(d)

Figure 11. Gas stations RSIS on (a) robbery and (c) theft, and their RSSS on (b) robbery and (d) theft across spatiotemporal models. 
Figure 12 displays the results of grocery stores across spatiotemporal models. The results indicated that theft RSIS of grocery stores in the default model was significantly higher than it was in the first shift $(p$-value $<0.05)$. It also showed robbery RSISs were higher than their theft counterparts during the second shift ( $p$-value $<0.05)$. We observed that robbery RSSS values were also significantly higher than theft values in the default ( $p$-value $<0.01)$, weekday ( $p$-value $<0.01)$, and third shift models ( $p$-value $<0.05)$. A comparative analysis with other features showed that theft and robbery intensity were significantly higher around grocery stores than around pubs in second shift models. The side difference tests revealed significantly higher theft and robbery RSISs on the FNS, FSES, and FSWS. For theft RSSS, grocery stores were found to have the highest values on the FSES.

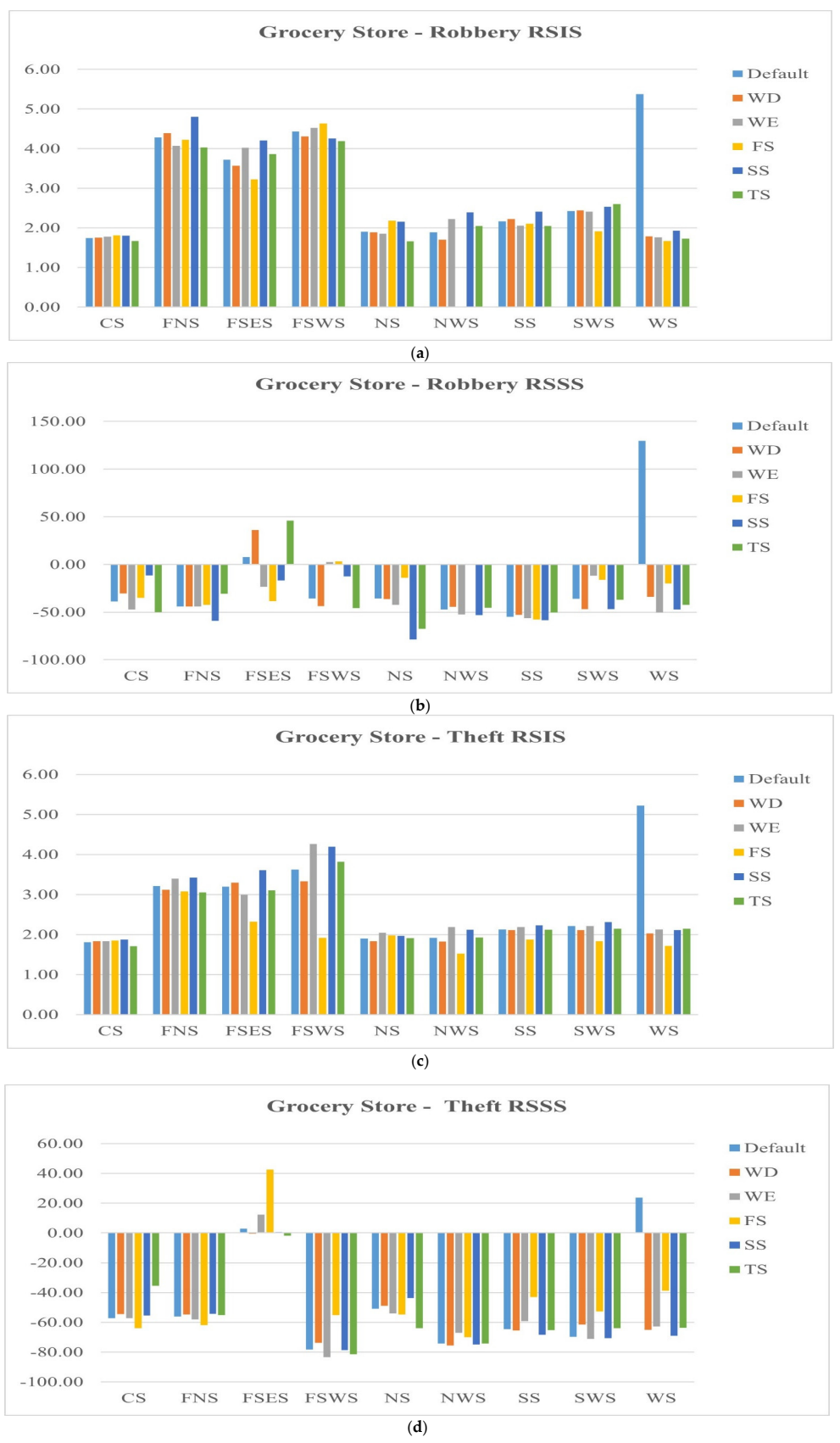

Figure 12. Grocery stores RSIS on (a) robbery and (c) theft, and their RSSS on (b) robbery and (d) theft across spatiotemporal models. 
The results of spatiotemporal influence analysis of pubs are displayed in Figure 13. They indicated that theft RSISs of pubs in default and weekday models were significantly higher than the weekday ( $p$-value $<0.05)$, and lower than the weekend $(p$-value $<0.05)$ model. We also found lower robbery RSSS values in the first shift than in the default model. It also reported greater robbery RSSSs in the second shift. The results also indicated robbery and theft RSSSs of pubs were significantly lower during weekdays, second shift, and third shift than that of fast-food restaurants. The Kruskal-Wallis test revealed significantly lower robbery RSISs of pubs on the SW and SWS, and theft RSISs on the SS, SWS, and NWS.

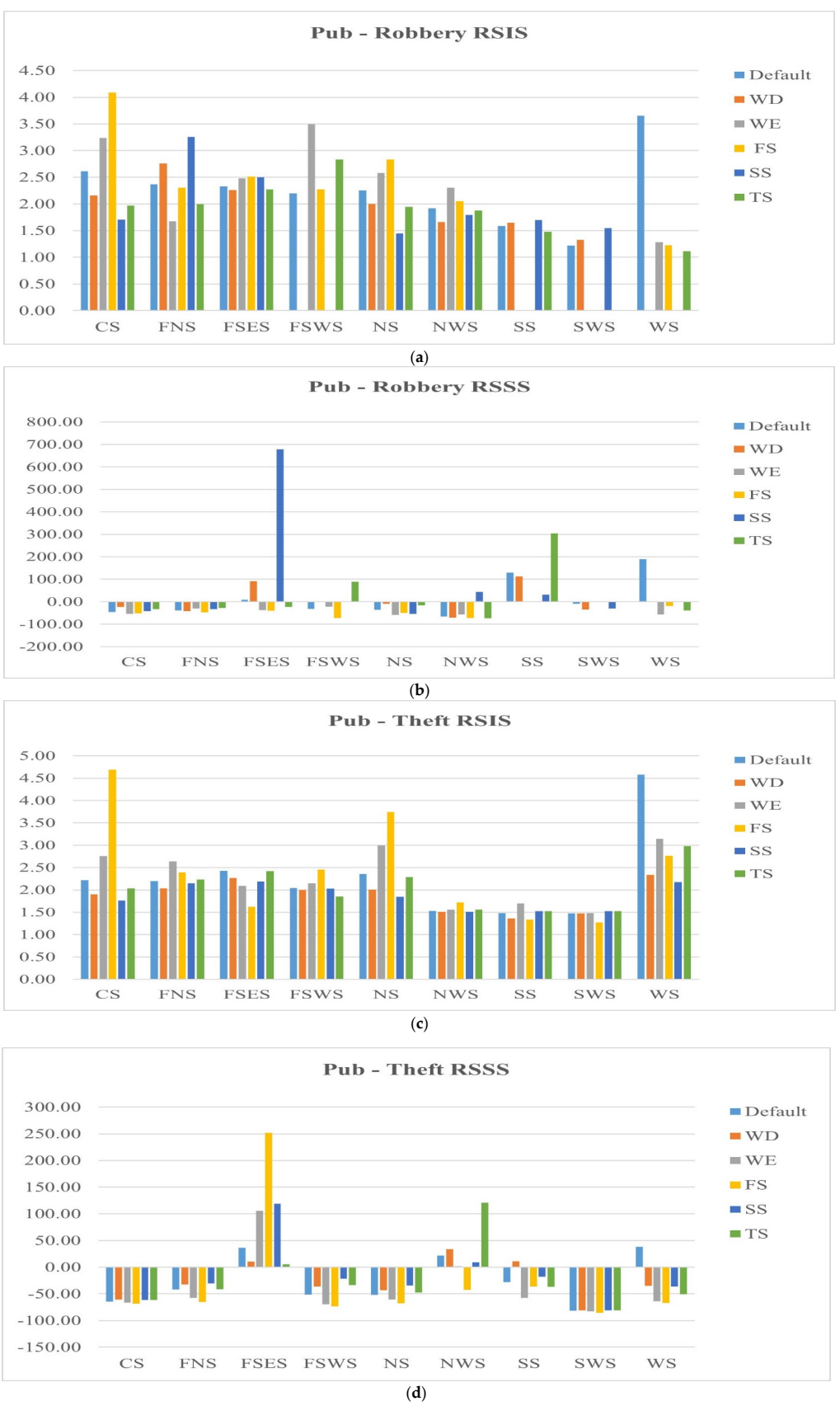

Figure 13. Pubs RSIS on (a) robbery and (c) theft, and their RSSS on (b) robbery and (d) theft across spatiotemporal models.

\subsection{Correlation Analysis with Concentrated Disadvantage (CD)}

The main results found that some RSIS and RSSS values of urban features for different crime types moderately correlated with both each other and with the concentrated 
disadvantage of the sides. We found strongly correlated theft and robbery RSISs around bus stops in all temporal models. For gas stations, the correlation analysis revealed an increased crime intensity in disadvantaged neighborhoods (Figures 14 and 15). Likewise, a strong correlation was observed between $C D$ and theft $\left(\rho_{\text {Theft, } C D}=0.92\right)$ and robbery $\left(\rho_{\text {Robbery, }} \mathrm{CD}=0.76\right)$ intensities in the second shift models.

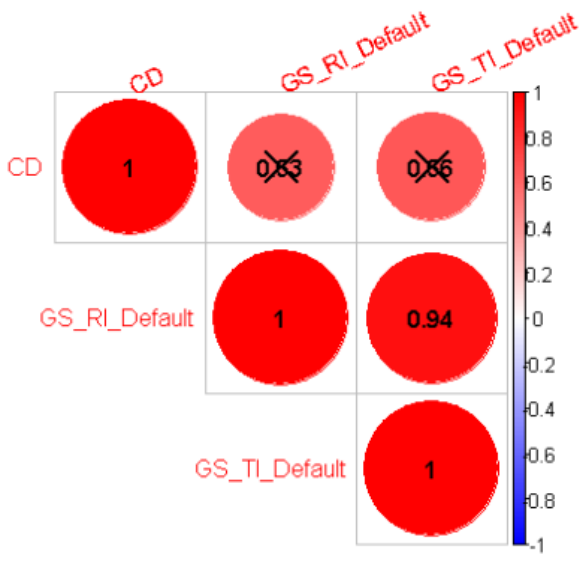

(a)

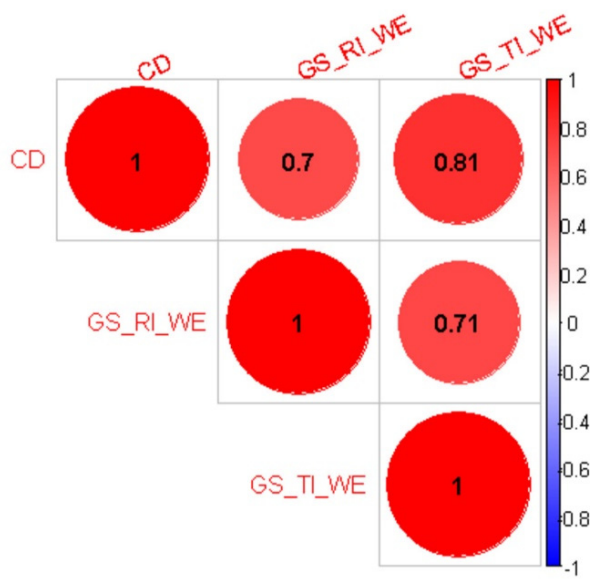

(c)

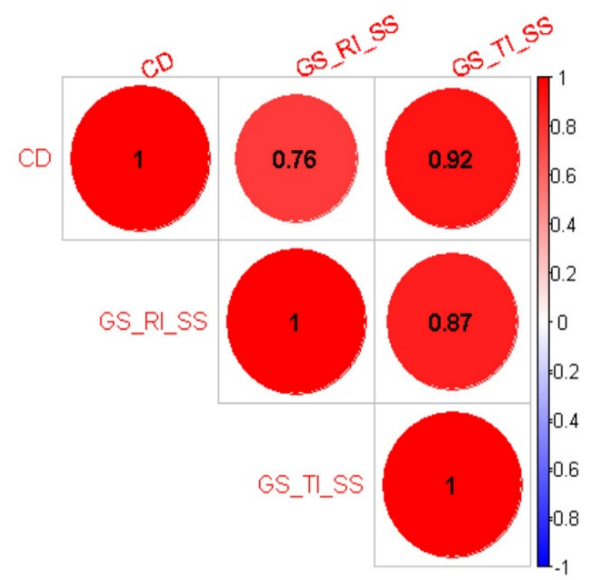

(e)

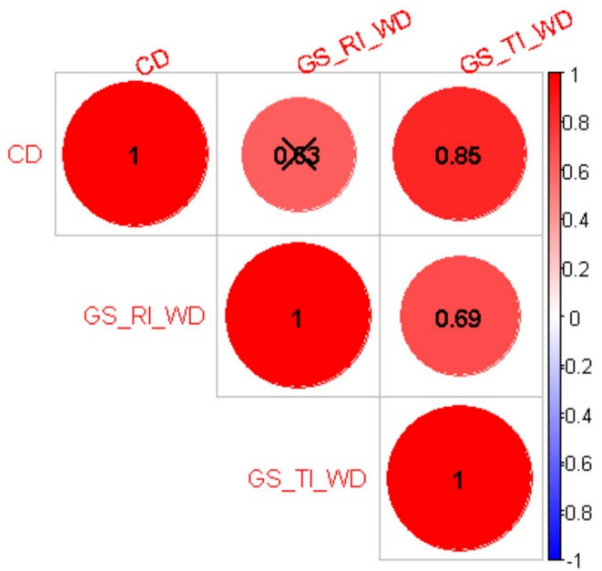

(b)

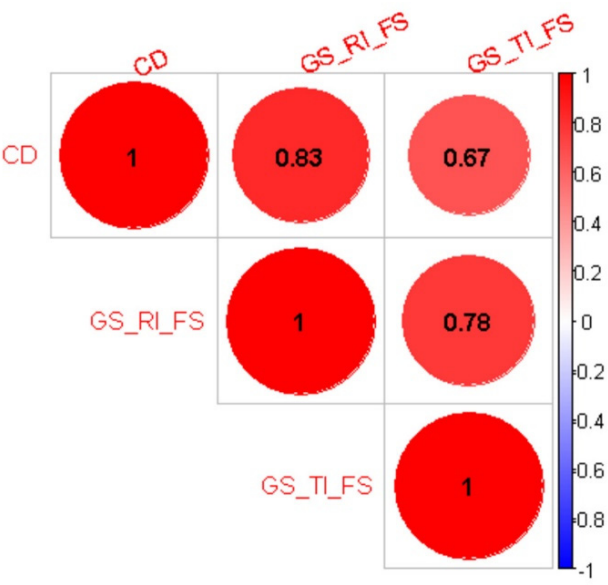

(d)

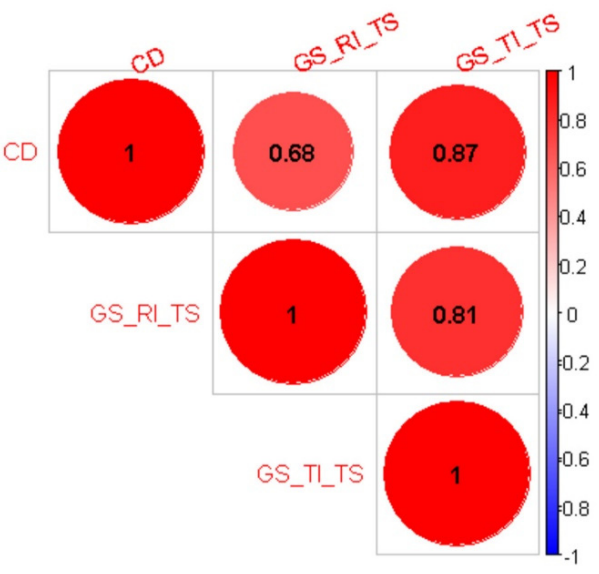

(f)

Figure 14. Correlograms between concentrated disadvantage (CD) and the RSIS values of gas stations in (a) default, (b) weekday, (c) weekend, (d) first shift, (e) second shift, and (f) third shift models. GS = gas station, RI = robbery RSIS, TI = theft RSIS, RS = Robbery RSSS, TS = theft RSSS, WD = weekday, WE = weekend, FS = first shift, SS = second shift, and TS = third shift. The cell labels follow the naming convention of: urban feature_risk score_temporal model. For example, GS_TI_Default refers to theft RSIS of gas stations in the default model). 


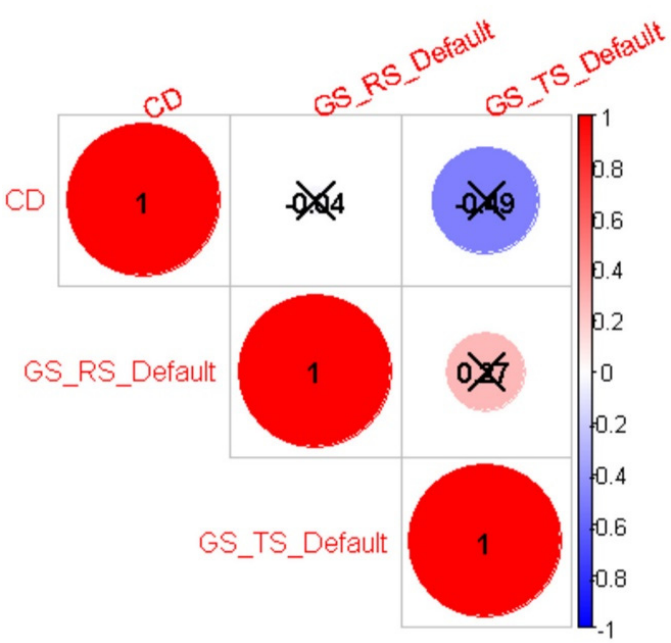

(a)

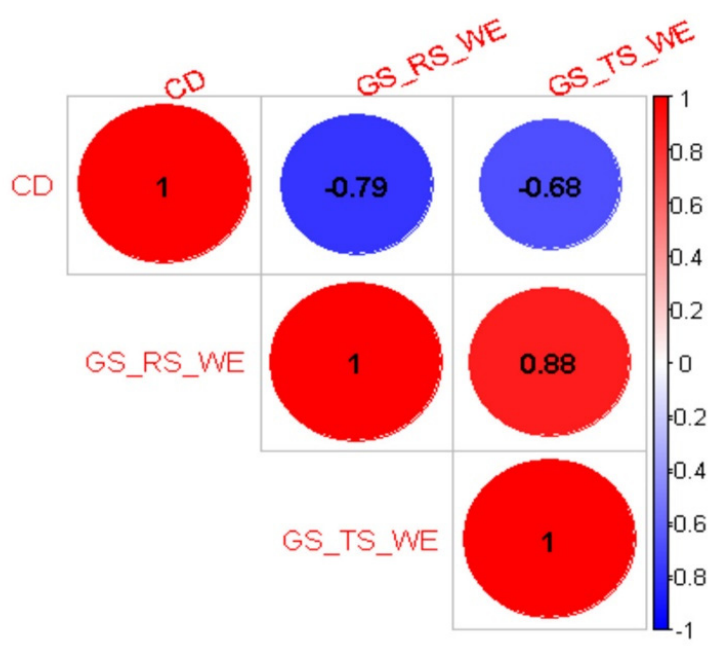

(c)

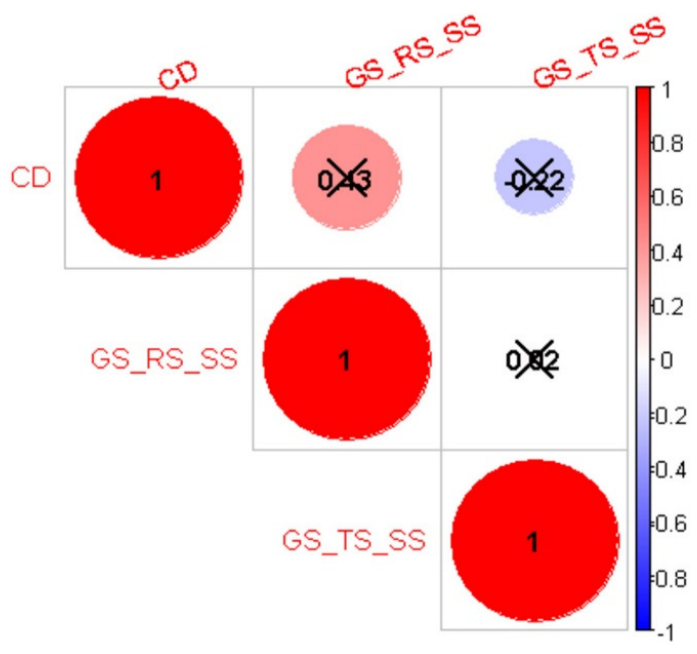

(e)

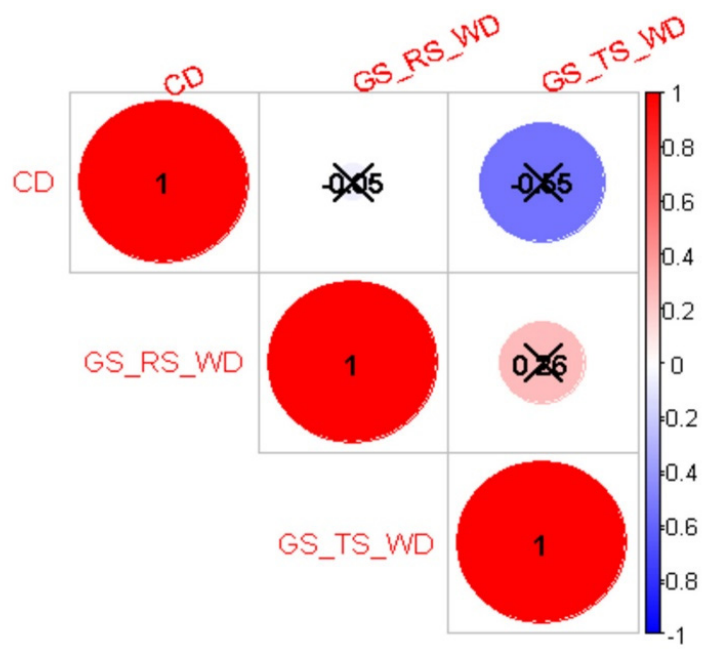

(b)

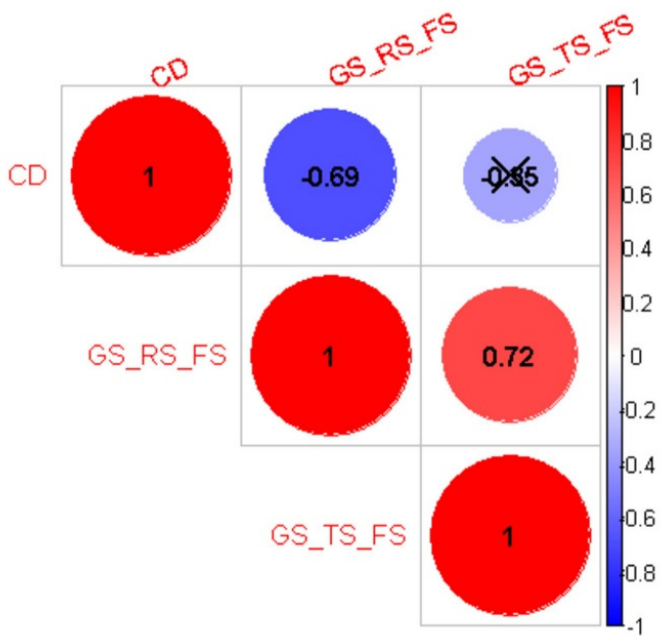

(d)

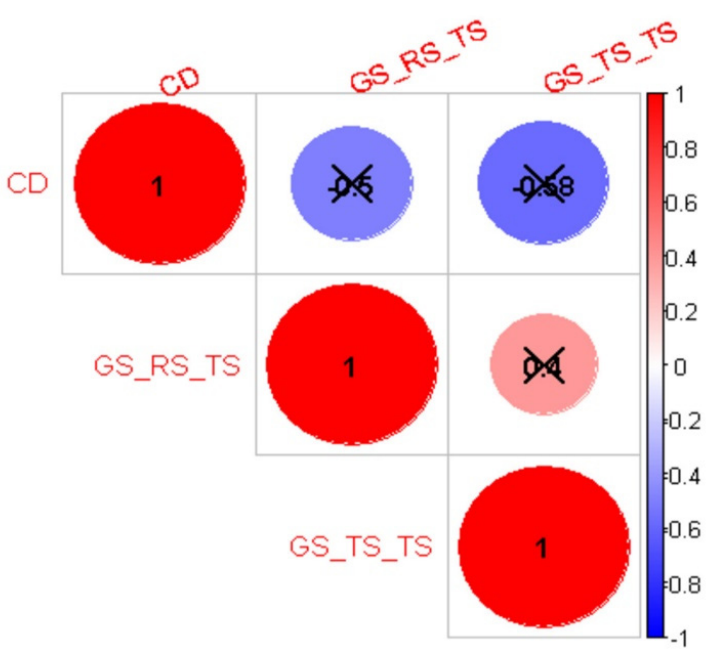

(f)

Figure 15. Correlograms between concentrated disadvantage (CD) and the RSSS values of gas stations in (a) default, (b) weekday, (c) weekend, (d) first shift, (e) second shift, and (f) third shift models. GS = gas station, RS = robbery RSSS, TS = theft RSSS, WD = weekday, WE = weekend, FS = first shift, SS = second shift, and TS = third shift. The cell labels follow the naming convention of: urban feature_risk score_temporal model. For example, GS_Ts_Default refers to theft RSSS of gas stations in the default model). 
In contrast, CD showed a negative correlation with robbery RSSS in the first shift $\left(\rho_{\text {Robbery, }} \mathrm{CD}=-0.69\right)$, and theft and robbery RSSS during the weekend $\left(\rho_{\text {Robbery, }} \mathrm{CD}=-0.79\right.$ and $\left.\rho_{\text {Theft }}=-0.68\right)$. For pubs, the only significant correlations with $C D$ were observed in theft $\left(\rho_{\text {Theft, }} \mathrm{CD}=-0.89\right)$ and robbery $\left(\rho_{\text {Robbery, }} \mathrm{CD}=-0.72\right)$ intensities in the first shift and second shift models, respectively.

\section{Discussion}

The bivariate network $\mathrm{K}$ analysis indicated possible dead zones in terms of spatial influence, which refer to certain spatiotemporal configurations where urban features do not broadcast any crime risk signals in their vicinities. Moreover, we found differential crime clusters around urban features that varied with the sides, time of the day, or day of the week. For instance, the default model identified insignificant theft and robbery clusters around gas stations across the CS. A weekly model, however, further indicated that robbery incidents had a significant cluster on the same side during weekdays. Similarly, although all the temporal models, except the default model, identified insignificant robbery clusters around gas stations on the NS, they found all theft clusters significant on the same side. These inconsistent crime clusters are well aligned with the previous research $[39,44,66-68]$ that showed unique intraday and weekly crime patterns around urban features across different regions. Another important result showed that, except for insignificant clusters around gas stations in a few spatiotemporal models, theft clusters were more consistent around all urban features than robbery clusters were. This underlines the situational crime opportunity, emphasizing the differential reward definition of offenders across different crime types [17]. Seemingly, theft criminals are less influenced by situational factors than robbers. Robbers, on the other hand, use violence and intimidation against victims, which may result in a physical struggle between involved parties. This struggle may draw larger attention from outsiders who can act as capable guardians [6]. Robbers are thus more sensitive to unfavorable situations than thieves due to higher associated risks.

The RSIS results indicated bus stops had significantly less spatial influence in nearly all temporal models when compared to other urban features, particularly fast-food restaurants [69]. On the contrary, many positive RSSS, particularly in theft, on all the sides, except on the CS and FNS, showed that it had a greater spatial diffusion effect throughout a spatial extent. This finding contradicted the distance decay effect that was empirically validated by previous research $[1,2,4,28,46]$. However, a body of research similarly reported some urban features (e.g., schools and pubs, etc.) have an increased spatial influence in further areas [5,45]. As a possible explanation, the existence of a bus stop may represent a haven for potential victims because of the presence of other people waiting for or getting off the bus who can act as informal security agents [14]. This increased number of capable guardians drives potential offenders to the more desolate places (i.e., alleyways and connection roads, etc.) causing a spatial spillover effect into nearby areas. Another interesting result indicated a positive robbery RSSSs of pubs on the SS in all temporal models. In contrast, their theft RSSSs strongly supported the distance decay effect on the same side. In sum, these results clearly showed that the risk intensity and risk strength dramatically changed based on space, time, and crime type.

The results of comparative RSSS analysis through the Wilcoxon signed rank and Kruskal-Wallis test provided mixed support for spatiotemporal differences conditioned by crime type [70]. The insignificant intraday differences were consistent with the findings of Bernasco, Ruiter, and Block [38], who found only limited intraday crime level differences around urban features during weekdays and the time of day. In this study, we found an intraday RSIS difference only for fast-food restaurants, which had significantly less theft intensity in the first shift than in others. Given that most of the fast-food restaurants were closed during late-night hours (00:00-07:59), such a result was not surprising. We found, however, considerable evidence for temporal differences in RSIS and RSSS around urban features. For example, a Wilcoxon signed rank test indicated higher robbery intensity around pubs during weekends when compared to weekdays. These findings lend em- 
pirical support for cyclic crime opportunity patterns that recur on a weekly basis around places $[39,44,66]$.

Spatiotemporal RSIS and RSSS analysis found a higher spatial influence of urban features on FNS, FSWS and, FSES, which are located in the north and south boundaries of Chicago, IL. Examining the possible interactions between side-level characteristics and the degree of spatial influence, the correlation analysis found a strong positive correlation between theft and robbery RSISs of gas stations and concentrated disadvantage. On the other hand, an inverse relationship was reported between theft and robbery RSISs of pubs and $C D$, but only in the first shift model. Given the CS is the most advantaged side of Chicago, IL and is the heart of the city in terms of business, nightlife, and entertainment, the increased robbery and theft intensity around pubs is not surprising due to the larger presence of intoxicated persons who may be unable defend themselves properly $[20,21]$. These results provided mixed support for previous research $[15,16]$ that identified a negative association between concentrated disadvantage and spatial influence. These contradicting results showed that the effect of concentrated disadvantage on spatial influence is mediated by the type of urban feature.

\section{Conclusions}

The current study introduced a crime-specific spatiotemporal approach for signallike spatial influence broadcasted from urban features (i.e., RSSS). To test this approach, we created 54 spatiotemporal models aggregating robbery and theft incidents at various spatial (i.e., sides of Chicago) and temporal (i.e., default, intraday, and weekly models) configurations. After eliminating insignificant spatiotemporal crime clusters by using network $\mathrm{K}$ analysis, we fitted distance-aware risk signal functions that model the spatial influence of an urban feature within a spatial extent. Devised from these functions are two novel scores, RSIS and RSSS, which quantified the intensity and strength of spatial influence signals. The main results of spatiotemporal influence analysis confirmed the existence of possible dead zones, where spatial influence of urban features on particular crime types does not exist at all. The next important finding indicated that the distance decay effect was conditioned by the type of urban feature and spatiotemporal context. For instance, bus stops had a demonstrated distance decay effect on robbery and theft across all temporal levels on the CS and FNS, but not on the other sides. We found that the direction of the relationship between spatial influence and concentrated disadvantage may depend on the type of urban features.

\subsection{Research Implications}

This study has some research implications. Firstly, it provided strong empirical support for the need for spatial influence analysis with a crime-specific spatiotemporal approach that was implied by the notion of environmental backcloth [7-9]. Accordingly, a crime generator or attractor in one context may remain irrelevant in another. Furthermore, it was clearly shown that the distance decay effect was mainly influenced by the type of urban features. We found an increased spatial diffusion effect for urban features with further distances across some spatiotemporal models, as well as intracity spatial influence differences across the sides of Chicago, IL. This finding was well-aligned with Feng et al. [68] who reported similar regional differences across the five boroughs of New York City, NY. Lastly, this study showed that spatial influence was mediated by concentrated disadvantage only for some urban features in some periods.

\subsection{Practical Implications}

The current study provides many useful insights for law enforcement professionals. First, a preliminary spatiotemporal clustering approach may help eliminate or augment patrol routes depending on the situation. Second, the proposed risk signal functions allowed for the quantification and comparison of the spatial influence of urban features at any given bandwidth across selected spatiotemporal units by modeling different cumulative crime 
densities within a spatial extent. Third, when aggregated at the street segment level, RSIS and RSSS values quantified the overall crime risk level of a segment. The aggregated values could then be used to create various spatiotemporal crime hotspot maps on street networks. It thus allows for the effective usage of resources along with more targeted interventions by informing decision-makers about optimal patrolling routes for any given period across the regions of a city. Moreover, an in-depth analysis of these places that are consistently ranked at the top by RSIS and RSSS may provide additional insights into these criminogenic environmental settings. As a possible crime prevention through environmental design (CPTED) [71] practice, these values may guide safety upgrades through environmental enhancements such as streetlights [28,72] or additional CCTV cameras [39].

\subsection{Limitations}

This study has several limitations. First and foremost, the performance of risk signal functions was heavily reliant upon the spatial and temporal precision of data, given that lower precision levels may jeopardize the validity of the estimated functions. Second, the modifiable areal unit problem (MAUP) [73] and modifiable temporal unit problem [74] also pose important threats to the validity of the analysis. Third, the computational intensity of network K analysis and the exponentially increasing number of space $x$ time $x$ crime $x$ urban feature configurations were inhibitive factors that hampered using spatiotemporal units at finer resolution levels. Fourth, the set of urban features that we included in the spatiotemporal analysis can be extended to include additional features. For example, Fox et al. [75] found vacancy as the key driver of violent crime across the north and south sides of St. Louis, MO. Lastly, the sample is limited to Chicago, IL, which significantly curbs the generalizability of this study to other cities. We, therefore, highly recommend replication studies in other urban contexts.

\subsection{Future Research}

Although we selected appropriate spatial and temporal units to overcome the data sparsity [38] and computational intractability of K-function [65], an analysis with a finer spatiotemporal granularity level may still promise noteworthy relationships and provide useful insights in future research. Another potential research avenue is to examine the alternative forms of the proposed risk signal function. For instance, a nonlinear function, rather than a linear one as in the current study, may better capture a curvilinear spatial influence within a spatial extent. With the increasing availability of GPS data to researchers, it is now becoming possible to measure the level of human activity along streets with greater accuracy. An analysis utilizing this measure would also provide valuable information about the interplay between spatial influence and ambient population in crime risk across streets.

Author Contributions: Conceptualization, Tugrul Cabir Hakyemez and Bertan Badur; data curation, Tugrul Cabir Hakyemez; formal analysis, Tugrul Cabir Hakyemez; funding acquisition, Bertan Badur; investigation, Tugrul Cabir Hakyemez; methodology, Tugrul Cabir Hakyemez and Bertan Badur; supervision, Bertan Badur; visualization, Tugrul Cabir Hakyemez; writing—original draft, Tugrul Cabir Hakyemez; writing — review \& editing, Tugrul Cabir Hakyemez and Bertan Badur. All authors have read and agreed to the published version of the manuscript.

Funding: This research was funded by Bogazici University Scientific Research Fund, grant number 15385.

Data Availability Statement: The data is presented in this study is available in a publicly accessible repository in Figshare at 10.6084/m9.figshare.14582886., accessed on 4 July 2021.

Acknowledgments: We would like to thank Jim Ward and Cagdas Dedeoglu for their constructive comments and valuable supports in preparing this manuscript.

Conflicts of Interest: The authors declare no conflict of interest. 
Appendix A

Table A1. The spatiotemporal network K results matrix.

\begin{tabular}{|c|c|c|c|c|c|c|c|c|c|c|c|c|c|}
\hline & \multirow[b]{2}{*}{ Sides } & \multicolumn{6}{|c|}{ Robbery } & \multicolumn{6}{|c|}{ Theft } \\
\hline & & Default & WD & WE & FS & SS & TS & Default & WD & WE & FS & SS & TS \\
\hline \multirow{9}{*}{$\begin{array}{l}\text { مे } \\
\text { के } \\
\text { D } \\
0\end{array}$} & Center & $\checkmark$ & $\checkmark$ & $\checkmark$ & $\checkmark$ & $\checkmark$ & $\checkmark$ & $\checkmark$ & $\checkmark$ & $\checkmark$ & $\checkmark$ & $\checkmark$ & $\checkmark$ \\
\hline & Far North & 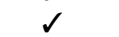 & $d$ & $\checkmark$ & $d$ & $\checkmark$ & $\checkmark$ & $\checkmark$ & 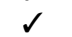 & $\checkmark$ & 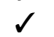 & 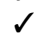 & 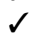 \\
\hline & Far South East & $\checkmark$ & $\checkmark$ & $\checkmark$ & $\checkmark$ & $\checkmark$ & $\checkmark$ & $\checkmark$ & $\checkmark$ & $\checkmark$ & $\checkmark$ & $\checkmark$ & $\checkmark$ \\
\hline & Far South West & $\checkmark$ & $\checkmark$ & $\checkmark$ & $\checkmark$ & $\checkmark$ & $\checkmark$ & $\checkmark$ & 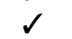 & $d$ & 2 & 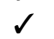 & 2 \\
\hline & North & $\checkmark$ & $\checkmark$ & $\checkmark$ & $\checkmark$ & $\checkmark$ & $\checkmark$ & $\checkmark$ & $\checkmark$ & $\checkmark$ & $\checkmark$ & $\checkmark$ & $\checkmark$ \\
\hline & North West & $\checkmark$ & 2 & 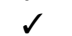 & $d$ & $\checkmark$ & $\checkmark$ & $\checkmark$ & 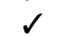 & $\checkmark$ & 1 & 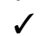 & 2 \\
\hline & South & $\checkmark$ & $\checkmark$ & $\checkmark$ & $\checkmark$ & $\checkmark$ & $\checkmark$ & 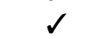 & $\checkmark$ & $d$ & 2 & 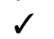 & 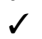 \\
\hline & South West & $\checkmark$ & $\checkmark$ & $\checkmark$ & $\checkmark$ & $\checkmark$ & $\checkmark$ & $\checkmark$ & $\checkmark$ & $\checkmark$ & $\checkmark$ & $\checkmark$ & $\checkmark$ \\
\hline & West & $\checkmark$ & $\checkmark$ & $\checkmark$ & $\checkmark$ & $\checkmark$ & $\checkmark$ & $\checkmark$ & $\checkmark$ & $\checkmark$ & $\checkmark$ & $\checkmark$ & $\checkmark$ \\
\hline \multirow{9}{*}{ 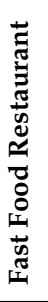 } & Center & $\checkmark$ & $\checkmark$ & $\checkmark$ & $\checkmark$ & $\checkmark$ & $\checkmark$ & $\checkmark$ & $\checkmark$ & $\checkmark$ & $\checkmark$ & $\checkmark$ & $\checkmark$ \\
\hline & Far North & $\checkmark$ & $\checkmark$ & $\checkmark$ & $\checkmark$ & $\checkmark$ & $\checkmark$ & $\checkmark$ & $\checkmark$ & $\checkmark$ & $\checkmark$ & $\checkmark$ & $\checkmark$ \\
\hline & Far South East & $\checkmark$ & $\checkmark$ & $\checkmark$ & $\checkmark$ & $\checkmark$ & $\checkmark$ & $\checkmark$ & $\checkmark$ & 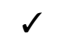 & $\checkmark$ & $\checkmark$ & $\checkmark$ \\
\hline & Far South West & $\checkmark$ & $\checkmark$ & $\checkmark$ & $\checkmark$ & $\checkmark$ & $\checkmark$ & $\checkmark$ & $\checkmark$ & $\checkmark$ & $\checkmark$ & $\checkmark$ & $\checkmark$ \\
\hline & North & $\checkmark$ & $\checkmark$ & $\checkmark$ & $\checkmark$ & $\checkmark$ & $\checkmark$ & $\checkmark$ & $\checkmark$ & $\checkmark$ & $\checkmark$ & $\checkmark$ & $\checkmark$ \\
\hline & North West & $\checkmark$ & $\checkmark$ & $\checkmark$ & $\checkmark$ & $\checkmark$ & $\checkmark$ & $\checkmark$ & $\checkmark$ & $\checkmark$ & $\checkmark$ & $\checkmark$ & $\checkmark$ \\
\hline & South & $\checkmark$ & $\checkmark$ & $\checkmark$ & $\checkmark$ & $\checkmark$ & $\checkmark$ & $\checkmark$ & $\checkmark$ & $\checkmark$ & $\checkmark$ & $\checkmark$ & $\checkmark$ \\
\hline & South West & $\checkmark$ & $\checkmark$ & $\checkmark$ & $\checkmark$ & $\checkmark$ & $\checkmark$ & $\checkmark$ & $\checkmark$ & $\checkmark$ & $\checkmark$ & $\checkmark$ & $\checkmark$ \\
\hline & West & $\checkmark$ & $\checkmark$ & $\checkmark$ & $\checkmark$ & $\checkmark$ & $\checkmark$ & $\checkmark$ & $\checkmark$ & $\checkmark$ & $\checkmark$ & $\checkmark$ & $\checkmark$ \\
\hline \multirow{9}{*}{ 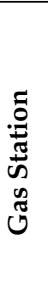 } & Center & $x$ & $\checkmark$ & $x$ & $x$ & $x$ & $x$ & $x$ & $x$ & $x$ & $x$ & $x$ & $x$ \\
\hline & Far North & $\checkmark$ & $\checkmark$ & $\checkmark$ & $\checkmark$ & $x$ & $x$ & $\checkmark$ & $\checkmark$ & $\checkmark$ & $\checkmark$ & $\checkmark$ & $\checkmark$ \\
\hline & Far South East & $\checkmark$ & $\checkmark$ & $\checkmark$ & $\checkmark$ & $\checkmark$ & $\checkmark$ & $\checkmark$ & $\checkmark$ & $\checkmark$ & $\checkmark$ & $\checkmark$ & $\checkmark$ \\
\hline & Far South West & $\checkmark$ & $\checkmark$ & $\checkmark$ & $\checkmark$ & $\checkmark$ & $\checkmark$ & $\checkmark$ & $\checkmark$ & $\checkmark$ & $\checkmark$ & $\checkmark$ & $\checkmark$ \\
\hline & North & $\checkmark$ & $\times$ & $x$ & $x$ & $x$ & $x$ & $\checkmark$ & $x$ & $d$ & $\checkmark$ & $x$ & $x$ \\
\hline & North West & $\checkmark$ & $\checkmark$ & $\checkmark$ & $\checkmark$ & $\checkmark$ & $\checkmark$ & $\checkmark$ & $\checkmark$ & $\checkmark$ & $\checkmark$ & $\checkmark$ & $\checkmark$ \\
\hline & South & $\checkmark$ & $\checkmark$ & $\checkmark$ & $\checkmark$ & $\checkmark$ & $\checkmark$ & $\checkmark$ & $\checkmark$ & $\checkmark$ & $\checkmark$ & $\checkmark$ & $\checkmark$ \\
\hline & South West & $\checkmark$ & $\checkmark$ & $\checkmark$ & $\checkmark$ & $\checkmark$ & $\checkmark$ & $\checkmark$ & $\checkmark$ & $\checkmark$ & $\checkmark$ & $\checkmark$ & $\checkmark$ \\
\hline & West & $\checkmark$ & $\checkmark$ & $\checkmark$ & $\checkmark$ & $\checkmark$ & $\checkmark$ & $\checkmark$ & $\checkmark$ & $\checkmark$ & $\checkmark$ & $\checkmark$ & $\checkmark$ \\
\hline \multirow{9}{*}{ 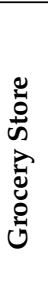 } & Center & $\checkmark$ & $\checkmark$ & $\checkmark$ & $\checkmark$ & $\checkmark$ & $\checkmark$ & $\checkmark$ & $\checkmark$ & $\checkmark$ & $\checkmark$ & $\checkmark$ & $\checkmark$ \\
\hline & Far North & $\checkmark$ & $\checkmark$ & $\checkmark$ & $\checkmark$ & $\checkmark$ & $\checkmark$ & $\checkmark$ & $\checkmark$ & $\checkmark$ & $\checkmark$ & $\checkmark$ & $\checkmark$ \\
\hline & Far South East & $d$ & 1 & 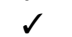 & $d$ & $\checkmark$ & $\checkmark$ & 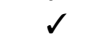 & 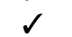 & $\checkmark$ & $\checkmark$ & $\checkmark$ & $\checkmark$ \\
\hline & Far South West & $\checkmark$ & $\checkmark$ & $\checkmark$ & $\checkmark$ & $\checkmark$ & $\checkmark$ & $\checkmark$ & 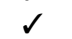 & $d$ & $\checkmark$ & $\checkmark$ & $\checkmark$ \\
\hline & North & $\checkmark$ & $\checkmark$ & $\checkmark$ & $\checkmark$ & $\checkmark$ & $\checkmark$ & $\checkmark$ & $\checkmark$ & $\checkmark$ & $\checkmark$ & $\checkmark$ & $\checkmark$ \\
\hline & North West & $\checkmark$ & $\checkmark$ & $\checkmark$ & $x$ & $\checkmark$ & $\checkmark$ & $\checkmark$ & $\checkmark$ & $\checkmark$ & $\checkmark$ & $\checkmark$ & $\checkmark$ \\
\hline & South & $\checkmark$ & $\checkmark$ & $\checkmark$ & $\checkmark$ & $\checkmark$ & 1 & $\checkmark$ & 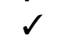 & $d$ & $d$ & $d$ & 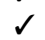 \\
\hline & South West & $\checkmark$ & $\checkmark$ & $\checkmark$ & $\checkmark$ & $\checkmark$ & $\checkmark$ & $\checkmark$ & $\checkmark$ & $\checkmark$ & $\checkmark$ & $\checkmark$ & $\checkmark$ \\
\hline & West & $\checkmark$ & $\checkmark$ & $\checkmark$ & $\checkmark$ & $\checkmark$ & $\checkmark$ & $\checkmark$ & $\checkmark$ & $\checkmark$ & $\checkmark$ & $\checkmark$ & $\checkmark$ \\
\hline \multirow{9}{*}{ 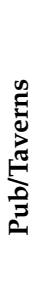 } & Center & $\checkmark$ & $\checkmark$ & $\checkmark$ & $\checkmark$ & $\checkmark$ & $\checkmark$ & $\checkmark$ & $\checkmark$ & $\checkmark$ & $\checkmark$ & $\checkmark$ & $\checkmark$ \\
\hline & Far North & 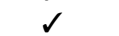 & 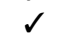 & $s$ & $d$ & $\checkmark$ & $\checkmark$ & $\checkmark$ & $\checkmark$ & $\checkmark$ & 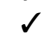 & $\checkmark$ & $\checkmark$ \\
\hline & Far South East & $\checkmark$ & $\checkmark$ & $\checkmark$ & $\checkmark$ & $\checkmark$ & $\checkmark$ & $\checkmark$ & $\checkmark$ & $\checkmark$ & 2 & $d$ & $\checkmark$ \\
\hline & Far South West & $\checkmark$ & $\times$ & $\checkmark$ & $\checkmark$ & $x$ & $\checkmark$ & $\checkmark$ & 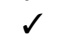 & $d$ & 2 & $d$ & 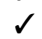 \\
\hline & North & $\checkmark$ & $\checkmark$ & $\checkmark$ & $\checkmark$ & $\checkmark$ & $\checkmark$ & $\checkmark$ & $\checkmark$ & $\checkmark$ & $\checkmark$ & $\checkmark$ & $\checkmark$ \\
\hline & North West & $\checkmark$ & $\checkmark$ & $\checkmark$ & $\checkmark$ & $\checkmark$ & $\checkmark$ & $\checkmark$ & $\checkmark$ & $\checkmark$ & $\checkmark$ & $\checkmark$ & $\checkmark$ \\
\hline & South & 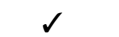 & 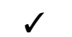 & $x$ & $x$ & $\checkmark$ & $\checkmark$ & $\checkmark$ & $\checkmark$ & $\checkmark$ & $\checkmark$ & $s$ & $d$ \\
\hline & South West & $\checkmark$ & $\checkmark$ & $x$ & $x$ & $\checkmark$ & $x$ & $\checkmark$ & $\checkmark$ & $\checkmark$ & $\checkmark$ & $\checkmark$ & $\checkmark$ \\
\hline & West & 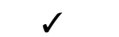 & $x$ & $s$ & $\checkmark$ & $x$ & $\checkmark$ & $s$ & 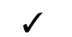 & 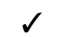 & 2 & $d$ & 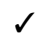 \\
\hline
\end{tabular}

Note: WD = Weekday, WE: Weekend, FS = First Shift (00:00-17:59), SS = Second Shift (08:00-15:59), TS = Third Shift (16:00-23:59), $\checkmark=$ Significant relationship, $X=$ non-significant relationship 


\section{Appendix B}

Table A2. The spatiotemporal RSIS results matrix.

\begin{tabular}{|c|c|c|c|c|c|c|c|c|c|c|c|c|c|}
\hline & & & & & & & & & & The & & & \\
\hline & Sides & Default & WD & WE & FS & SS & TS & Default & WD & WE & FS & SS & TS \\
\hline & Center & 1.74 & 1.81 & 1.73 & 1.80 & 1.94 & 1.69 & 1.62 & 1.63 & 1.58 & 1.56 & 1.62 & 1.62 \\
\hline & Far North & 2.21 & 2.43 & 1.83 & 2.45 & 2.07 & 2.12 & 1.77 & 1.76 & 1.78 & 1.69 & 1.92 & 1.64 \\
\hline & Far South East & 2.15 & 2.12 & 2.20 & 2.06 & 2.30 & 2.10 & 2.09 & 2.12 & 2.05 & 1.59 & 2.28 & 2.09 \\
\hline ? & Far South West & 2.07 & 2.10 & 2.01 & 2.03 & 1.99 & 16.56 & 1.79 & 1.75 & 1.93 & 1.51 & 1.94 & 13.00 \\
\hline$\omega$ & North & 1.58 & 1.52 & 1.65 & 1.71 & 1.51 & 1.48 & 1.56 & 1.54 & 1.59 & 1.52 & 1.58 & 1.56 \\
\hline$\stackrel{\infty}{0}$ & North West & 1.43 & 1.42 & 1.46 & 1.40 & 1.84 & 1.38 & 1.56 & 1.57 & 1.54 & 1.41 & 1.74 & 1.48 \\
\hline & South & 1.38 & 1.35 & 1.37 & 1.37 & 1.38 & 1.34 & 1.39 & 1.39 & 1.39 & 1.30 & 1.43 & 1.38 \\
\hline & South West & 1.42 & 1.42 & 1.48 & 1.38 & 1.49 & 1.49 & 1.51 & 1.49 & 1.56 & 1.25 & 1.62 & 1.51 \\
\hline & West & 1.40 & 1.45 & 1.32 & 1.36 & 1.40 & 1.42 & 1.29 & 1.31 & 1.26 & 1.21 & 1.36 & 1.26 \\
\hline & Center & 2.77 & 2.85 & 2.62 & 2.24 & 3.23 & 2.94 & 2.56 & 2.73 & 2.26 & 1.91 & 2.87 & 2.39 \\
\hline ฮ్ & Far North & 3.56 & 3.72 & 3.32 & 2.87 & 4.01 & 3.89 & 3.52 & 3.48 & 3.59 & 3.80 & 3.94 & 2.98 \\
\hline $\bar{\Xi}$ & Far South East & 5.13 & 4.55 & 6.08 & 3.87 & 5.96 & 5.04 & 6.48 & 6.15 & 6.69 & 3.50 & 7.05 & 6.92 \\
\hline$\vec{w}$ & Far South West & 4.07 & 4.49 & 3.99 & 3.79 & 6.38 & 2.96 & 3.05 & 2.97 & 3.06 & 2.25 & 3.19 & 3.31 \\
\hline$\simeq$ & North & 2.82 & 2.77 & 2.91 & 2.80 & 2.91 & 2.85 & 3.11 & 3.07 & 3.23 & 2.61 & 3.37 & 3.07 \\
\hline$\overline{0}$ & North West & 2.32 & 2.34 & 2.35 & 1.95 & 3.11 & 2.15 & 4.95 & 4.80 & 5.33 & 2.41 & 6.07 & 4.83 \\
\hline 这 & South & 2.08 & 1.97 & 2.22 & 2.04 & 1.90 & 2.20 & 2.42 & 2.44 & 2.52 & 1.99 & 2.63 & 2.36 \\
\hline$\vec{w}$ & South West & 2.41 & 2.45 & 2.46 & 2.19 & 2.75 & 2.43 & 3.71 & 3.59 & 3.98 & 1.84 & 4.27 & 3.92 \\
\hline & West & 3.56 & 1.92 & 1.60 & 1.55 & 2.00 & 1.77 & 4.83 & 3.04 & 2.77 & 2.27 & 3.47 & 2.68 \\
\hline & Center & 0.00 & 1.46 & 0.00 & 0.00 & 0.00 & 0.00 & 0.00 & 0.00 & 0.00 & 0.00 & 0.00 & 0.00 \\
\hline & Far North & 1.86 & 1.91 & 1.77 & 2.46 & 0.00 & 0.00 & 1.63 & 1.62 & 1.65 & 1.96 & 1.51 & 1.61 \\
\hline$\approx$ & Far South East & 3.23 & 3.16 & 3.59 & 4.04 & 3.03 & 2.83 & 2.65 & 2.69 & 2.54 & 2.99 & 2.81 & 2.37 \\
\hline 乎 & Far South West & 3.76 & 3.70 & 4.25 & 3.33 & 3.56 & 4.40 & 2.66 & 2.65 & 2.67 & 2.64 & 2.76 & 2.52 \\
\hline कే & North & 1.51 & 0.00 & 0.00 & 0.00 & 0.00 & 0.00 & 1.13 & 1.05 & 1.39 & 1.80 & 0.00 & 0.00 \\
\hline 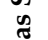 & North West & 2.21 & 2.21 & 2.19 & 1.90 & 2.47 & 2.30 & 2.08 & 2.09 & 2.07 & 2.01 & 1.73 & 2.16 \\
\hline & South & 1.82 & 1.76 & 1.92 & 2.15 & 1.89 & 1.69 & 1.92 & 1.91 & 1.95 & 1.47 & 2.04 & 1.90 \\
\hline & South West & 2.12 & 1.85 & 2.36 & 1.94 & 2.09 & 2.14 & 2.30 & 2.29 & 2.33 & 2.28 & 2.25 & 2.32 \\
\hline & West & 4.01 & 2.29 & 2.28 & 2.54 & 1.93 & 2.30 & 4.32 & 1.62 & 1.71 & 1.76 & 1.65 & 1.60 \\
\hline & Center & 1.74 & 1.75 & 0.00 & 1.81 & 1.80 & 1.67 & 1.81 & 1.84 & 1.84 & 1.85 & 1.88 & 1.71 \\
\hline & Far North & 4.28 & 4.39 & 4.07 & 4.22 & 4.80 & 4.03 & 3.22 & 3.12 & 3.40 & 3.08 & 3.43 & 3.05 \\
\hline$\cong$ & Far South East & 3.72 & 3.57 & 4.03 & 3.22 & 4.21 & 3.87 & 3.19 & 3.29 & 2.99 & 2.32 & 3.61 & 3.11 \\
\hline के & Far South West & 4.43 & 4.31 & 4.53 & 4.64 & 4.26 & 4.19 & 3.62 & 3.33 & 4.27 & 1.92 & 4.19 & 3.82 \\
\hline 2 & North & 1.90 & 0.00 & 0.00 & 2.18 & 2.16 & 1.66 & 1.90 & 1.83 & 2.05 & 1.98 & 1.97 & 1.91 \\
\hline$\check{\Xi}$ & North West & 1.89 & 1.71 & 2.22 & 0.00 & 2.39 & 2.05 & 1.92 & 1.83 & 2.19 & 1.52 & 2.12 & 1.93 \\
\hline 8 & South & 2.17 & 2.22 & 2.05 & 2.11 & 2.41 & 2.05 & 2.13 & 2.11 & 2.19 & 1.88 & 2.23 & 2.12 \\
\hline & South West & 2.42 & 2.44 & 2.41 & 1.91 & 2.54 & 2.60 & 2.21 & 2.11 & 2.21 & 1.84 & 2.31 & 2.15 \\
\hline & West & 5.37 & 1.79 & 1.77 & 1.67 & 1.93 & 1.73 & 5.22 & 2.03 & 2.13 & 1.71 & 2.11 & 2.15 \\
\hline & Center & 2.61 & 2.16 & 3.23 & 4.09 & 1.71 & 1.97 & 2.22 & 1.90 & 2.76 & 4.69 & 1.76 & 2.03 \\
\hline & Far North & 2.37 & 2.76 & 1.67 & 2.30 & 3.26 & 2.00 & 2.20 & 2.04 & 2.63 & 2.39 & 2.15 & 2.23 \\
\hline & Far South East & 2.33 & 2.26 & 2.48 & 2.51 & 2.50 & 2.27 & 2.43 & 2.26 & 2.09 & 1.62 & 2.19 & 2.42 \\
\hline 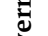 & Far South West & 2.20 & 0.00 & 3.50 & 2.27 & 0.00 & 2.83 & 2.04 & 2.00 & 2.15 & 2.45 & 2.03 & 1.86 \\
\hline (త) & North & 2.25 & 2.00 & 2.58 & 2.83 & 1.44 & 1.94 & 2.36 & 2.00 & 2.99 & 3.75 & 1.84 & 2.29 \\
\hline$\frac{6}{8}$ & North West & 1.92 & 1.66 & 2.30 & 2.05 & 1.79 & 1.87 & 1.53 & 1.51 & 1.56 & 1.72 & 1.51 & 1.56 \\
\hline 3 & South & 1.58 & 1.65 & 0.00 & 0.00 & 1.70 & 1.48 & 1.48 & 1.36 & 1.70 & 1.34 & 1.53 & 1.52 \\
\hline & South West & 1.22 & 1.33 & 0.00 & 0.00 & 1.55 & 0.00 & 1.47 & 1.47 & 1.48 & 1.27 & 1.52 & 1.52 \\
\hline & West & 3.66 & 0.00 & 1.28 & 1.23 & 0.00 & 1.11 & 4.58 & 2.34 & 3.14 & 2.76 & 2.18 & 2.98 \\
\hline
\end{tabular}

Note: WD = Weekday, WE: Weekend, FS = First Shift (00:00-17:59), SS = Second Shift (08:00-15:59), TS = Third Shift (16:00-23:59). 
Table A3. The spatiotemporal RSSS results matrix.

\begin{tabular}{|c|c|c|c|c|c|c|c|c|c|c|c|c|c|}
\hline & \multirow[b]{2}{*}{ Sides } & \multicolumn{6}{|c|}{ Robbery } & \multicolumn{6}{|c|}{ Theft } \\
\hline & & Default & WD & WE & FS & ss & TS & Default & WD & $\mathrm{WE}$ & FS & ss & TS \\
\hline \multirow{9}{*}{ 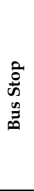 } & Center & -2.62 & -1.22 & 3.41 & -1.07 & -20.70 & 2.41 & -30.84 & -30.47 & -32.21 & 33.36 & -32.39 & -34.54 \\
\hline & Far North & -4.66 & -4.44 & -5.26 & -22.41 & -12.34 & 20.02 & -10.14 & -6.55 & -16.79 & -26.61 & -7.34 & -4.87 \\
\hline & Far South East & -0.46 & 7.13 & -67.90 & 1.20 & 1.93 & -3.09 & 20.17 & 27.04 & 7.40 & 38.63 & 18.16 & 18.05 \\
\hline & Far South West & 16.73 & 13.16 & -2.97 & 6.22 & 5.05 & 128.43 & 76.50 & 96.62 & 89.63 & 316.88 & 91.26 & 113.40 \\
\hline & North & 11.19 & 20.36 & -3.95 & -18.50 & 64.16 & 53.11 & 54.39 & 49.89 & 42.75 & 23.82 & 41.99 & 70.11 \\
\hline & North West & 84.68 & 74.59 & 109.42 & 51.56 & 6.97 & 66.47 & 53.25 & 54.50 & 51.28 & 53.17 & 70.69 & 46.34 \\
\hline & South & 20.46 & 33.65 & 5.01 & 7.55 & 10.43 & 26.56 & 90.14 & 81.51 & 110.47 & 69.86 & 102.87 & 85.03 \\
\hline & South West & 2.64 & 2.33 & 14.15 & -32.45 & 27.52 & 12.37 & 76.78 & 79.00 & 53.71 & 114.18 & 59.62 & 48.66 \\
\hline & West & 9.24 & 5.47 & 16.69 & 15.41 & 12.57 & 3.71 & 36.81 & 37.29 & 36.17 & 47.36 & 43.92 & 25.46 \\
\hline \multirow{9}{*}{ 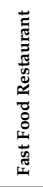 } & Center & -38.22 & -48.14 & -36.47 & -33.36 & -29.65 & -50.03 & 2.49 & 0.36 & 7.98 & 31.00 & -3.79 & -8.63 \\
\hline & Far North & -61.38 & -64.72 & -52.40 & -31.48 & -57.54 & -67.63 & -41.16 & -41.23 & -41.31 & -44.27 & -43.51 & -35.58 \\
\hline & Far South East & -56.32 & -55.54 & -48.06 & -2.09 & -69.18 & -42.66 & -58.00 & -54.32 & -62.67 & -11.16 & -56.44 & -63.04 \\
\hline & Far south West & -89.52 & -91.61 & -35.55 & -89.42 & -91.24 & -81.75 & -77.55 & -79.34 & -75.71 & -72.70 & -76.12 & -80.33 \\
\hline & North & -67.75 & -71.90 & -57.39 & -60.69 & -70.45 & -72.05 & -59.12 & -59.32 & -56.99 & -53.63 & -61.06 & -62.41 \\
\hline & North West & -59.02 & -64.90 & -0.95 & -46.89 & -79.89 & 40.81 & -75.37 & -71.98 & -79.16 & -66.64 & -74.75 & -77.33 \\
\hline & South & -51.79 & -57.37 & -42.05 & -72.04 & 1.23 & -45.67 & -35.22 & -39.02 & -33.20 & -32.70 & -51.69 & 21.65 \\
\hline & South West & -81.63 & -80.83 & -80.97 & -85.00 & -75.58 & -80.77 & -86.57 & -86.52 & -86.71 & -76.33 & -86.68 & -87.87 \\
\hline & West & 74.57 & -58.19 & -7.47 & -46.53 & -67.34 & -16.09 & 7.60 & -53.87 & -84.38 & -54.67 & -58.38 & -51.37 \\
\hline \multirow{9}{*}{ 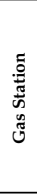 } & Center & 0.00 & 89.45 & 0.00 & 0.00 & 0.00 & 0.00 & 0.00 & 0.00 & 0.00 & 0.00 & 0.00 & 0.00 \\
\hline & Far North & -33.12 & -36.37 & -25.50 & -26.68 & 0.00 & 0.00 & -23.11 & -28.73 & -7.66 & -36.94 & -18.50 & -17.84 \\
\hline & Far South East & -51.37 & -48.28 & -55.81 & -67.12 & 534.04 & -56.54 & -7.98 & -3.75 & -19.27 & -53.44 & 12.69 & -3.63 \\
\hline & Far South West & 98.39 & 418.20 & -7.03 & 3.38 & 247.40 & 54.44 & -10.97 & -15.58 & 0.14 & 12.23 & 0.11 & -28.61 \\
\hline & North & -37.71 & 0.00 & 0.00 & 0.00 & 0.00 & 0.00 & -3.47 & 5.24 & 36.65 & 39.62 & 0.00 & 0.00 \\
\hline & North West & -9.27 & 116.58 & -47.44 & -11.13 & -52.88 & 44.49 & -22.21 & -18.15 & -29.51 & -33.05 & 142.11 & -29.71 \\
\hline & South & -12.06 & 70.96 & -58.32 & -33.04 & -46.92 & -56.72 & -46.96 & -45.76 & -49.11 & 43.43 & -45.57 & -49.97 \\
\hline & South West & -41.10 & -31.14 & -56.32 & -53.88 & -62.11 & -56.02 & -68.11 & -67.93 & -68.41 & -73.24 & -61.46 & -70.17 \\
\hline & West & 10.53 & -60.42 & -67.64 & -72.17 & 93.28 & -61.87 & 5.16 & -55.29 & -59.49 & -70.87 & -52.09 & -53.18 \\
\hline \multirow{9}{*}{ 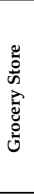 } & Center & -38.82 & -30.43 & -47.26 & -34.95 & -11.55 & -50.02 & -57.06 & -54.56 & -57.07 & -64.00 & -55.43 & -35.39 \\
\hline & Far North & -44.10 & -44.09 & -44.07 & -42.25 & -59.23 & -30.88 & -55.96 & -54.74 & -58.15 & -61.85 & -54.28 & -55.08 \\
\hline & Far South East & 7.66 & 36.23 & -23.35 & -38.53 & -16.73 & 46.00 & 2.97 & -0.41 & 12.39 & 42.60 & 0.70 & -1.86 \\
\hline & Far South West & -35.46 & -43.76 & 2.67 & 3.42 & -12.62 & -45.93 & -78.20 & -73.70 & -83.50 & -55.05 & -78.63 & -81.33 \\
\hline & North & -35.67 & -36.30 & -42.33 & -13.95 & -78.56 & -67.46 & -50.99 & -48.93 & -53.94 & -54.75 & -43.71 & -63.92 \\
\hline & North West & -47.19 & -44.30 & -52.40 & 0.00 & -53.02 & -45.29 & -74.30 & -75.51 & -66.95 & -69.98 & -74.77 & -74.21 \\
\hline & South & -55.03 & $\begin{array}{l}-52.92 \\
\end{array}$ & -56.25 & -57.65 & -58.44 & -50.46 & -64.66 & -65.51 & -59.17 & -43.02 & -68.37 & -65.18 \\
\hline & South West & -35.86 & -46.74 & -11.97 & -15.98 & -46.97 & -37.08 & -69.82 & -61.37 & -71.04 & -52.61 & -70.72 & -63.83 \\
\hline & West & 129.55 & -33.88 & -50.45 & -20.03 & -47.05 & -42.43 & 23.75 & -64.93 & -62.82 & -38.87 & -69.00 & -63.67 \\
\hline \multirow{9}{*}{ 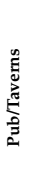 } & Center & -45.66 & -22.87 & -53.52 & -52.01 & -41.13 & -32.50 & -64.51 & -60.45 & -66.64 & -68.30 & -61.48 & -61.47 \\
\hline & Far North & -38.69 & -40.99 & -30.96 & -46.71 & -32.97 & -27.13 & -41.93 & -32.52 & -57.66 & -65.24 & -30.36 & -40.95 \\
\hline & Far South East & 8.73 & 91.32 & -37.52 & -40.00 & 677.99 & -23.79 & 36.42 & 10.31 & 105.73 & 251.67 & 119.07 & 5.60 \\
\hline & Far South West & -32.01 & 0.00 & -22.26 & -71.84 & 0.00 & 89.16 & -51.35 & -35.89 & -69.66 & -73.16 & -21.81 & -33.89 \\
\hline & North & -36.62 & -9.79 & -57.76 & -50.49 & -54.80 & -16.92 & -51.75 & -43.14 & -60.49 & -67.54 & -34.46 & -47.46 \\
\hline & North West & -65.86 & -71.38 & -56.39 & -71.88 & 43.83 & -73.14 & 21.96 & 34.09 & 1.73 & -42.16 & 8.97 & 120.68 \\
\hline & South & 129.35 & 112.56 & 0.00 & 0.00 & 30.94 & 304.44 & -27.92 & 11.37 & -57.40 & -35.98 & -17.83 & -36.72 \\
\hline & South West & -9.44 & -35.20 & 0.00 & 0.00 & -30.61 & 0.00 & -81.58 & -81.08 & -82.51 & -85.09 & -80.62 & -80.81 \\
\hline & West & 188.85 & 0.00 & -57.35 & -18.97 & 0.00 & -38.86 & 38.08 & -35.20 & -63.97 & -66.79 & -35.91 & -50.76 \\
\hline
\end{tabular}

Note: WD = Weekday, WE: Weekend, FS = First Shift (00:00-17:59), SS = Second Shift (08:00-15:59), TS = Third Shift (16:00-23:59).

\section{References}

1. Ratcliffe, J.H. The Spatial Extent of Criminogenic Places: A Changepoint Regression of Violence around Bars. Geogr. Anal. 2012, 44, 302-320. [CrossRef]

2. Groff, E.R. Measuring a place's exposure to facilities using geoprocessing models: An illustration using drinking places and crime. In Crime Modeling and Mapping Using Geospatial Technologies; Leitner, M., Ed.; Springer: Dordrecht, The Netherlands, 2013; pp. 269-295. [CrossRef]

3. Groff, E.R.; Lockwood, B. Criminogenic Facilities and Crime across Street Segments in Philadelphia. J. Res. Crime Delinq. 2014, 51, 277-314. [CrossRef]

4. Groff, E. Exploring 'near': Characterizing the spatial extent of drinking place influence on crime. Aust. N. Z. J. Criminol. 2011, 44, 156-179. [CrossRef]

5. Wheeler, A.P. Quantifying the Local and Spatial Effects of Alcohol Outlets on Crime. Crime Delinquency 2019, 65, 845-871. [CrossRef]

6. Cohen, L.E.; Felson, M. Social Change and Crime Rate Trends: A Routine Activity Approach. Am. Sociol. Rev. 1979, 44, 588. [CrossRef]

7. Brantingham, P.J.; Brantingham, P.L. Environmental Criminology; Sage Publications: Beverly Hills, CA, USA, 1981.

8. Brantingham, P.L.; Brantingham, P.J. Nodes, paths and edges: Considerations on the complexity of crime and the physical environment. J. Environ. Psychol. 1993, 13, 3-28. [CrossRef]

9. Brantingham, P.; Brantingham, P. Criminality of place. Eur. J. Crim. Policy Res. 1995, 3, 5-26. [CrossRef]

10. Eck, J.E.; Clarke, R.V.; Guerette, R.T. Risky facilities: Crime concentration in homogeneous sets of establishments and facilities. Crime Prevention Studies 2007, 21, 225-264.

11. Timms, D. The Urban Mosaic: Towards a Theory of Residential Differentiation, 2nd ed.; CUP Archive: Cambridge, UK, 1975.

12. Pred, A. Social Reproduction and the Time-Geography of Everyday Life. Geogr. Ann. Ser. B Hum. Geogr. 1981, 63, 5. [CrossRef]

13. Hägerstraand, T. What about people in regional science? Pap. Reg. Sci. 1970, 24, 7-24. [CrossRef]

14. Jacobs, J. The Death and Life of Great American Cities; Vintage: New York, NY, USA, 1961.

15. Stucky, T.D.; Ottensmann, J.R. Land use and violent crime. Criminology 2009, 47, 1223-1264. [CrossRef]

16. Browning, C.R.; Byron, R.A.; Calder, C.A.; Krivo, L.J.; Kwan, M.-P.; Lee, J.-Y.; Peterson, R.D. Commercial Density, Residential Concentration, and Crime: Land Use Patterns and Violence in Neighborhood Context. J. Res. Crime Delinq. 2010, 47, 329-357. [CrossRef]

17. Clarke, R.V. Situational Crime Prevention. Crime Justice 1995, 19, 91-150. [CrossRef] 
18. Kinney, J.B.; Brantingham, P.L.; Wuschke, K.; Kirk, M.G.; Brantingham, P.J. Crime Attractors, Generators and Detractors: Land Use and Urban Crime Opportunities. Built Environ. 2008, 34, 62-74. [CrossRef]

19. Loukaitou-Sideris, A. Hot Spots of Bus Stop Crime. J. Am. Plan. Assoc. 1999, 65, 395-411. [CrossRef]

20. Roncek, D.W.; Pravatiner, M.A. Additional evidence that taverns enhance nearby crime. Sociol. Soc. Res. 1989, 73, $185-188$.

21. Roncek, D.W.; Maier, P.A. Bars, blocks, and crimes revisited: Linking the theory of routine activities to the empiricism of "hot spots". Criminology 1991, 29, 725-753. [CrossRef]

22. Rengert, G.F.; Piquero, A.R.; Jones, P.R. DISTANCE DECAY REEXAMINED. Criminology 1999, 37, 427-446. [CrossRef]

23. Rice, K.J.; Csmith, W.R. Socioecological Models of Automotive Theft: Integrating Routine Activity and Social Disorganization Approaches. J. Res. Crime Delinq. 2002, 39, 304-336. [CrossRef]

24. Weisburd, D.; Groff, E.R.; Yang, S.M. The Criminology of Place: Street Segments and Our Understanding of the Crime Problem; Oxford University Press: Oxford, UK, 2012.

25. Rengert, G.F.; Ratcliffe, J.; Chakravorty, S. Policing Illegal Drug Markets: Geographic Approaches to Crime Reduction; Criminal Justice Press: Monsey, NY, USA, 2005.

26. Newton, A.; Hirschfield, A. Measuring violence in and around licensed premises: The need for a better evidence base. Crime Prev. Community Saf. 2009, 11, 171-188. [CrossRef]

27. Mccord, E.S.; Ratcliffe, J.H. A Micro-Spatial Analysis of the Demographic and Criminogenic Environment of Drug Markets in Philadelphia. Aust. N. Z. J. Criminol. 2007, 40, 43-63. [CrossRef]

28. Xu, J.; Griffiths, E. Shooting on the Street: Measuring the Spatial Influence of Physical Features on Gun Violence in a Bounded Street Network. J. Quant. Criminol. 2017, 33, 237-253. [CrossRef]

29. Felson, M.; Boivin, R. Daily crime flows within a city. Crime Sci. 2015, 4, 31. [CrossRef]

30. Bernasco, W.; Block, R. Robberies in Chicago: A Block-Level Analysis of the Influence of Crime Generators, Crime Attractors, and Offender Anchor Points. J. Res. Crime Delinq. 2010, 48, 33-57. [CrossRef]

31. Yamada, I.; Thill, J.-C. Comparison of planar and network K-functions in traffic accident analysis. J. Transp. Geogr. 2004, 12, 149-158. [CrossRef]

32. Lu, Y.; Chen, X. On the false alarm of planar K-function when analyzing urban crime distributed along streets. Soc. Sci. Res. 2007, 36, 611-632. [CrossRef]

33. Tompson, L.; Partridge, H.; Shepherd, N. Hot routes: Developing a new technique for the spatial analysis of crime. Crime Mapp. J. Res. Pract. 2009, 1, 77-96.

34. Maki, N.; Okabe, A. A Spatio-Temporal Analysis of Aged Members of a Fitness Club in a Suburb. Proc. Geogr. Inf. Syst. Assoc. 2005, 14, 29-34.

35. Groff, E.R. Measuring the Influence of the Built Environment on Crime at Street Segments. Jerus. Rev. Leg. Stud. 2017, 15, 44-54. [CrossRef]

36. Ratcliffe, J. A Temporal Constraint Theory to Explain Opportunity-Based Spatial Offending Patterns. J. Res. Crime Delinq. 2006, 43, 261-291. [CrossRef]

37. Haberman, C.P.; Ratcliffe, J. Testing for temporally differentiated relationships among potentially criminogenic places and census block street robbery counts. Criminology 2015, 53, 457-483. [CrossRef]

38. Bernasco, W.; Ruiter, S.; Block, R. Do Street Robbery Location Choices Vary Over Time of Day or Day of Week? A Test in Chicago. J. Res. Crime Delinq. 2017, 54, 244-275. [CrossRef] [PubMed]

39. Corcoran, J.; Zahnow, R.; Kimpton, A.; Wickes, R.; Brunsdon, C. The temporality of place: Constructing a temporal typology of crime in commercial precincts. Environ. Plan. B Urban Anal. City Sci. 2021, 48, 9-24. [CrossRef]

40. Irvin-Erickson, Y.; La Vigne, N. A Spatio-temporal Analysis of Crime at Washington, DC Metro Rail: Stations' Crime-generating and Crime-attracting Characteristics as Transportation Nodes and Places. Crime Sci. 2015, 4, 14. [CrossRef]

41. Hart, T.C.; Miethe, T.D. Configural Behavior Settings of Crime Event Locations. J. Res. Crime Delinq. 2015, 52, 373-402. [CrossRef]

42. MacDonald, J.M.; Nicosia, N.; Ukert, B.D. Do Schools Cause Crime in Neighborhoods? Evidence from the Opening of Schools in Philadelphia. J. Quant. Criminol. 2018, 34, 717-740. [CrossRef]

43. Barnum, J.D.; Caplan, J.M.; Kennedy, L.W.; Piza, E.L. The crime kaleidoscope: A cross-jurisdictional analysis of place features and crime in three urban environments. Appl. Geogr. 2017, 79, 203-211. [CrossRef]

44. Hipp, J.R.; Kim, Y.-A. Explaining the temporal and spatial dimensions of robbery: Differences across measures of the physical and social environment. J. Crim. Justice 2019, 60, 1-12. [CrossRef]

45. Breetzke, G.D.; Edelstein, I.S. Do crime generators exist in a developing context? An exploratory study in the township of Khayelitsha, South Africa. Secur. J. 2020, 1-18. [CrossRef]

46. McCord, E.S.; Ratcliffe, J.H. Intensity value analysis and the criminogenic effects of land use features on local crime patterns. Crime Patterns Anal. 2009, 2, 17-30.

47. About Chicago: Facts and Statistics. Available online: https://www.chicago.gov/city/en/about/facts.html (accessed on 12 May 2021).

48. The "Sides" of Chicago. Chicago Studies. Available online: https://chicagostudies.uchicago.edu/sides (accessed on 12 May 2021).

49. Keating, A.D. Chicago Neighborhoods and Suburbs: A Historical Guide; University of Chicago Press: Chicago, IL, USA, 2008.

50. Sampson, R.J. Great American City: Chicago and the Enduring Neighborhood Effect; University of Chicago Press: Chicago, IL, USA, 2012.

51. Block, R. Street Gang Crime in Chicago; National Institute of Justice: Washington, DC, USA, 1993. 
52. Schnell, C.; Braga, A.A.; Piza, E.L. The Influence of Community Areas, Neighborhood Clusters, and Street Segments on the Spatial Variability of Violent Crime in Chicago. J. Quant. Criminol. 2017, 33, 469-496. [CrossRef]

53. Okabe, A.; Sugihara, K. Spatial Analysis Along Networks: Statistical and Computational Methods; John Wiley and Sons: Hoboken, NJ, USA, 2012.

54. Payroll and Timekeeping-Attendance. Available online: http://directives.chicagopolice.org/directives/data/a7a57b36-12cf4 df7-24112-cf4e-9398046d4f55fbaf.html (accessed on 3 July 2021).

55. Bernasco, W.; Block, R. Where offenders choose to attack: A discrete choice model of robberies in chicago. Criminology 2009, 47, 93-130. [CrossRef]

56. Kennedy, L.W.; Caplan, J.M.; Piza, E.L.; Buccine-Schraeder, H. Vulnerability and Exposure to Crime: Applying Risk Terrain Modeling to the Study of Assault in Chicago. Appl. Spat. Anal. Policy 2016, 9, 529-548. [CrossRef]

57. Kim, Y.-A. Examining the Relationship Between the Structural Characteristics of Place and Crime by Imputing Census Block Data in Street Segments: Is the Pain Worth the Gain? J. Quant. Criminol. 2016, 34, 67-110. [CrossRef]

58. Okabe, A.; Yamada, I. The K-Function Method on a Network and Its Computational Implementation. Geogr. Anal. 2010, 33, 271-290. [CrossRef]

59. Ripley's K Function. Wiley StatsRef: Statistics Reference. Available online: https://onlinelibrary.wiley.com/doi/abs/10.1002/97 81118445112.stat07751 (accessed on 12 May 2021).

60. Baddeley, A.; Diggle, P.J.; Hardegen, A.; Lawrence, T.; Milne, R.K.; Nair, G. On tests of spatial pattern based on simulation envelopes. Ecol. Monogr. 2014, 84, 477-489. [CrossRef]

61. Baddeley, A.J.; Turner, R. Spatstat: An R package for analyzing spatial point pattens. J. Stat. Softw. 2005, 12, 1-42. [CrossRef]

62. Kim, H.-J.; Fay, M.P.; Feuer, E.J.; Midthune, D.N. Permutation tests for joinpoint regression with applications to cancer rates. Stat. Med. 2000, 19, 335-351. [CrossRef]

63. Nelessen, A.C. Visions for a New American Dream; Planners Press, American Planning Association: Chicago, IL, USA, 1994.

64. Caplan, J.M. Mapping the spatial influence of crime correlates: A comparison of operationalization schemes and implications for crime analysis and criminal justice practice. Cityscape 2011, 13, 57-83.

65. He, Z.; Deng, M.; Xie, Z.; Wu, L.; Chen, Z.; Pei, T. Discovering the joint influence of urban facilities on crime occurrence using spatial co-location pattern mining. Cities 2020, 99, 102612. [CrossRef]

66. A Andresen, M.; Malleson, N. Intra-week spatial-temporal patterns of crime. Crime Sci. 2015, 4, 12. [CrossRef]

67. Yue, H.; Zhu, X.; Ye, X.; Guo, W. The Local Colocation Patterns of Crime and Land-Use Features in Wuhan, China. ISPRS Int. J. Geo-Inform. 2017, 6, 307. [CrossRef]

68. Feng, S.Q.; Piza, E.L.; Kennedy, L.W.; Caplan, J.M. Aggravating effects of alcohol outlet types on street robbery and aggravated assault in New York City. J. Crime Justice 2018, 42, 257-273. [CrossRef]

69. Song, G.; Bernasco, W.; Liu, L.; Xiao, L.; Zhou, S.; Liao, W. Crime Feeds on Legal Activities: Daily Mobility Flows Help to Explain Thieves' Target Location Choices. J. Quant. Criminol. 2019, 35, 831-854. [CrossRef]

70. De Melo, S.N.; Pereira, D.V.S.; Andresen, M.A.; Matias, L. Spatial/Temporal Variations of Crime: A Routine Activity Theory Perspective. Int. J. Offender Ther. Comp. Criminol. 2018, 62, 1967-1991. [CrossRef] [PubMed]

71. Jeffery, C.R. Crime Prevention through Environmental Design; Sage Publications: Beverly Hills, CA, USA, 1971.

72. Xu, Y.; Fu, C.; Kennedy, E.; Jiang, S.; Owusu-Agyemang, S. The impact of street lights on spatial-temporal patterns of crime in Detroit, Michigan. Cities 2018, 79, 45-52. [CrossRef]

73. Wong, D. The modifiable areal unit problem (MAUP). In SAGE Handbook of Spatial Analysis; Fotheringham, A., Rogerson, P.A., Eds.; Sage Publications: Thousand Oaks, CA, USA, 2009; pp. 105-123.

74. Cheng, T.; Adepeju, M. Modifiable Temporal Unit Problem (MTUP) and Its Effect on Space-Time Cluster Detection. PLoS ONE 2014, 9, e100465. [CrossRef]

75. Fox, B.; Trolard, A.; Simmons, M.; Meyers, J.E.; Vogel, M. Assessing the Differential Impact of Vacancy on Criminal Violence in the City of St. Louis, MO. Crim. Justice Rev. 2021, 46, 156-172. [CrossRef] 